\title{
Financial impediments in risk management mechanisms of Greek Small and Medium Enterprises
}

\author{
Karaoulanis Andreas \\ MBAMScEngMScBEng
}

\begin{abstract}
Micro Small and Medium Enterprises (SMEs) in contemporary Greece have difficulties in overcoming their financial risks via the use of their risk management mechanisms. The main reason for this failure is the presence of several financial impediments which prevent such risk management mechanisms to perform efficiently enough. So, the aim of this research is to unveil these financial impediments while the research question is "What are the financial impediments that interfere with the Greek SMEs' risk management mechanisms?"

The method that was used was the survey one by the use of questionnaires which were distributed face to face and by email. The data was analyzed by the use of the Dedoose software following a qualitative approach.

The findings showed that the SMEs that were investigated used only informal and non- sophisticated risk management mechanisms, while the financial impediments that prevented such mechanisms to operate efficiently enough were the general unstable financial and political climate, the capital controls and the SMEs' limited access to bank financing.

The results of this research can have very important societal implications as they can show to SMEs' owners the importance of the implementation of the right risk management mechanisms, something which can lead them to sustainable development and to general societal prosperity on the long run.
\end{abstract}

\section{Indexing terms/Keywords}

Financial impediments, risk management, SMEs, Greece.

\section{Academic Discipline And Sub-Disciplines}

Management. Risk management

\section{SUBJECT CLASSIFICATION}

Research

\section{TYPE (METHOD/APPROACH)}

Survey

\section{Acknowledgements}

First of all i want to thank God for keeping me safe and helping me with this research. I also want to thank my wife and kids for supporting me throughout this difficult process and my supervisor Dr. Sundgren D. for his guidance and professional attitude.

\section{GLOSSARY OF TERMS AND ABBREVIATIONS}

\section{CAQDAS Computer Assisted Qualitative Data Analysis System}

ESEE National Confederation of Hellenic Commerce

EU European Union

GSVEE Hellenic Confederation of Professionals, Craftsmen \& Merchants

GVA Gross Value Added

HBA Hellenic Banks Association

KEEE Union of Hellenic Chambers of Commerce

NBG National Bank of Greece

NSW New South Wales (Australia)

SBA Small Business Administration

SETE Association of Greek Tourist enterprises

SME Small and Medium Enterprise

TFGR Task Force for Greece of the European Commission

USD United States Dollar 

Value Added Tax

\section{Table of Contents}

1. INTRODUCTION

.7

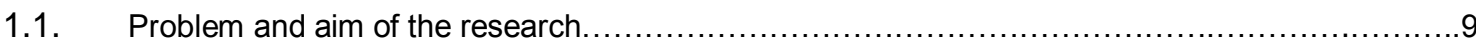

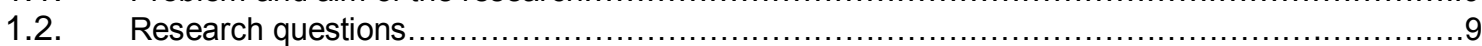

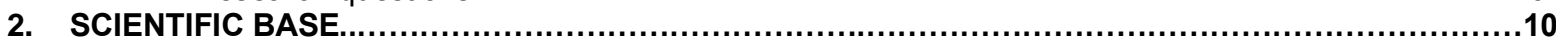

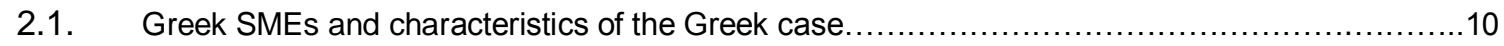

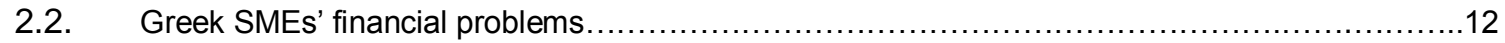

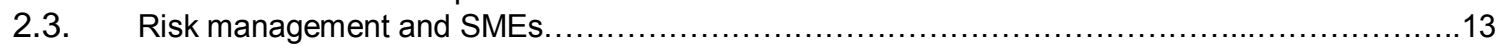

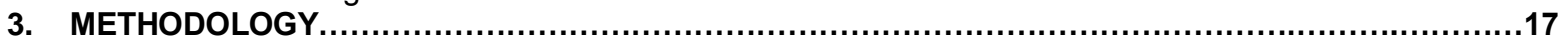

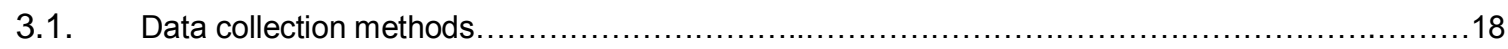

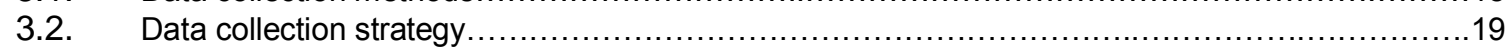

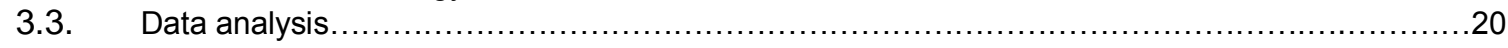

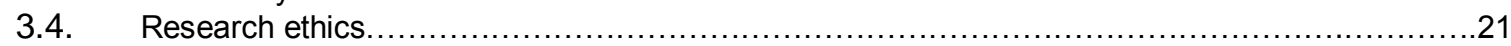

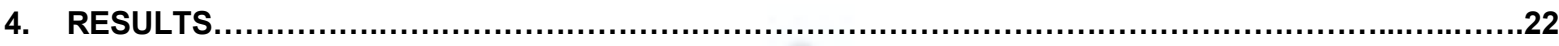

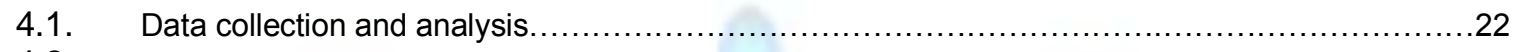

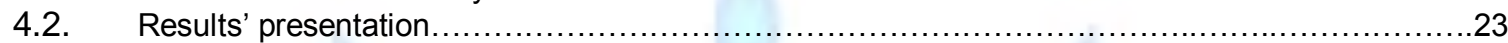

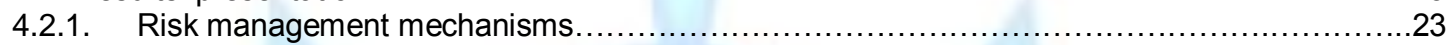

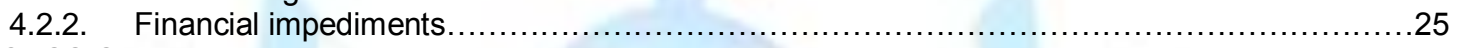

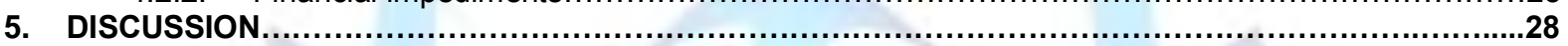

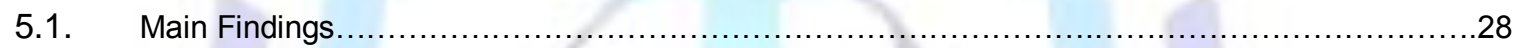

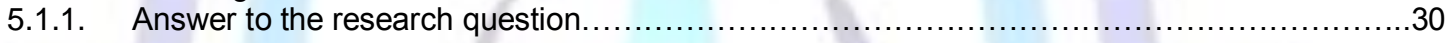

5.2. Connection between main findings and previous research on the topic...........................30

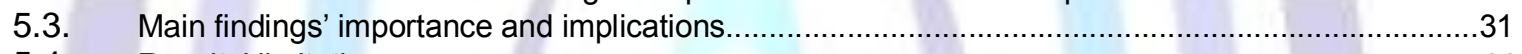

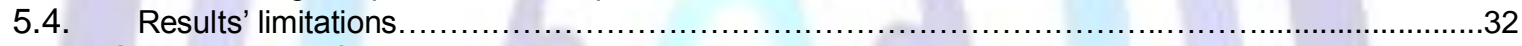

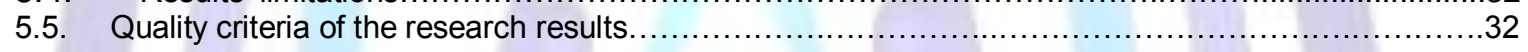

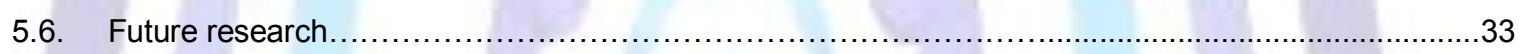

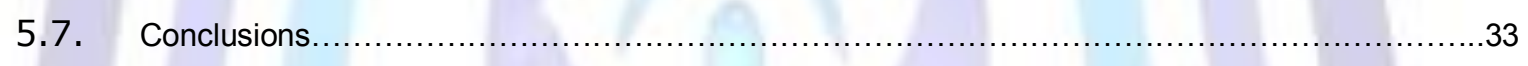

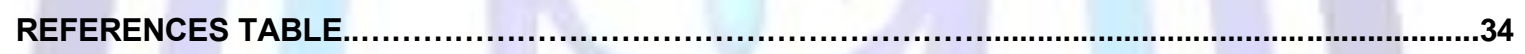

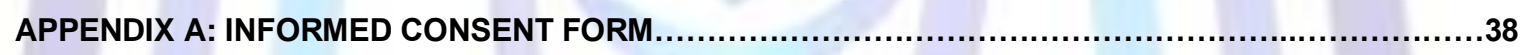

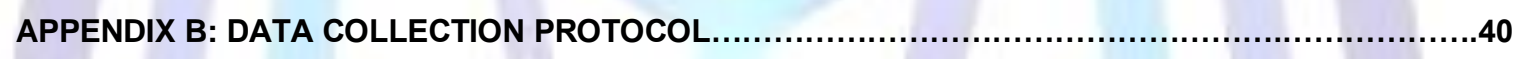

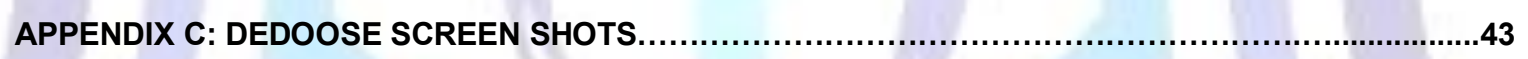

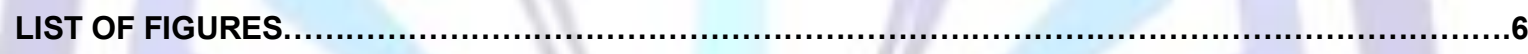

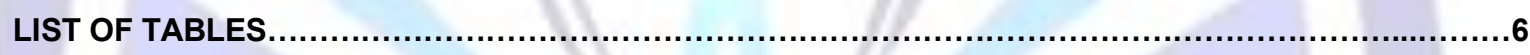

\section{List of Figures}

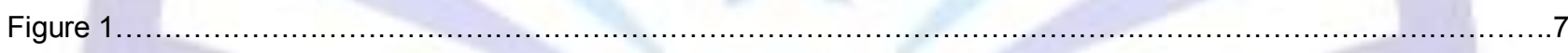

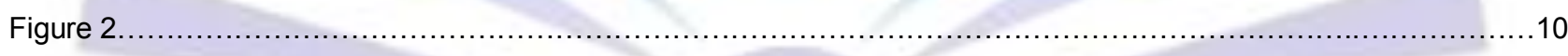

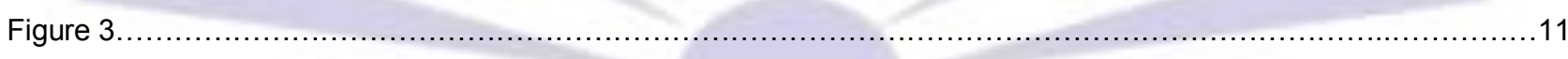

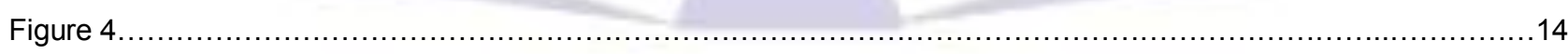

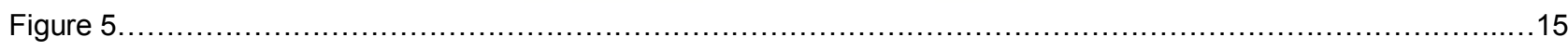

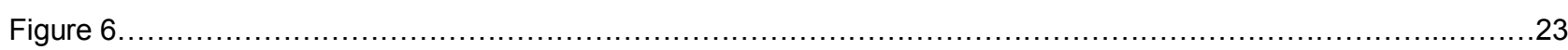

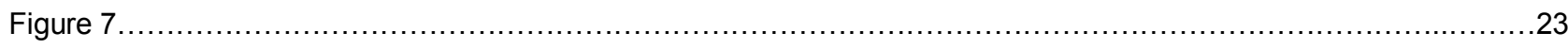

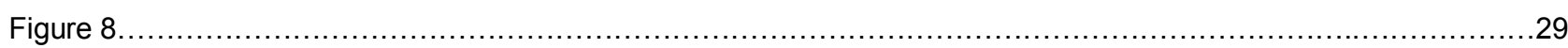

\section{List of Tables}

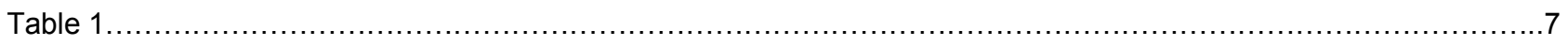

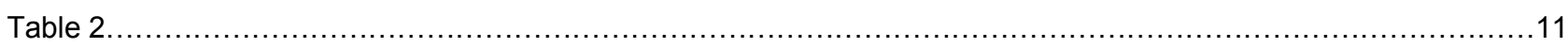

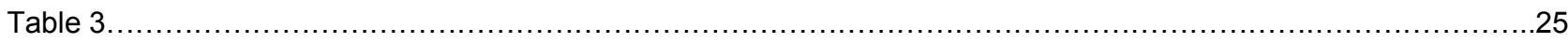

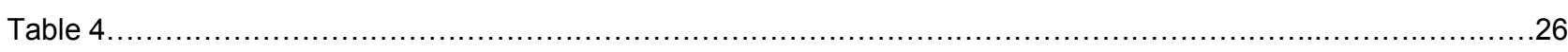

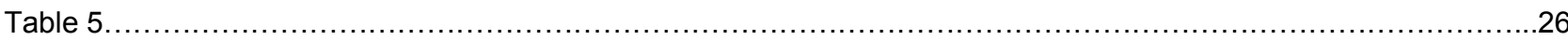


Tnternational Journal of Management and Information Technology Table 6

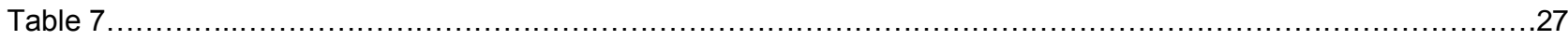

\section{INTRODUCTION}

As in European Union (EU) recommendation 2003/361, the main factors determining whether an enterprise is small and medium enterprise (SME), are staff headcount and either turnover or balance sheet total (ec.europa.eu, n.d.).

Table 1: Factors determining whether an enterprise is a SME or not (ec. europa.eu., n.d.)

\begin{tabular}{|c|c|c|c|}
\hline Company category & Staff headcount & Turnover & Balance sheet total \\
\hline Medium-sized & $<250$ & $\leq € 50 \mathrm{~m}$ & $\leq € 43 \mathrm{~m}$ \\
\hline Small & $<50$ & $\leq € 10 \mathrm{~m}$ & $\leq € 10 \mathrm{~m}$ \\
\hline Micro & $<10$ & $\leq € 2 \mathrm{~m}$ & $\leq € 2 \mathrm{~m}$ \\
\hline
\end{tabular}

According to Gama et al. (2012, cited in Falkner et al., 2015), $99 \%$ of the economic activities in the EU, can be traced back to SMEs. This accounts to the two thirds of all jobs in the private sector. In Greece nowadays, SMEs are covering the $57 \%$ of the total employment (Protothema.gr, 2016), while SMEs with less than 10 employees cover the almost $97 \%$ of Greek enterprises (Figure 1).

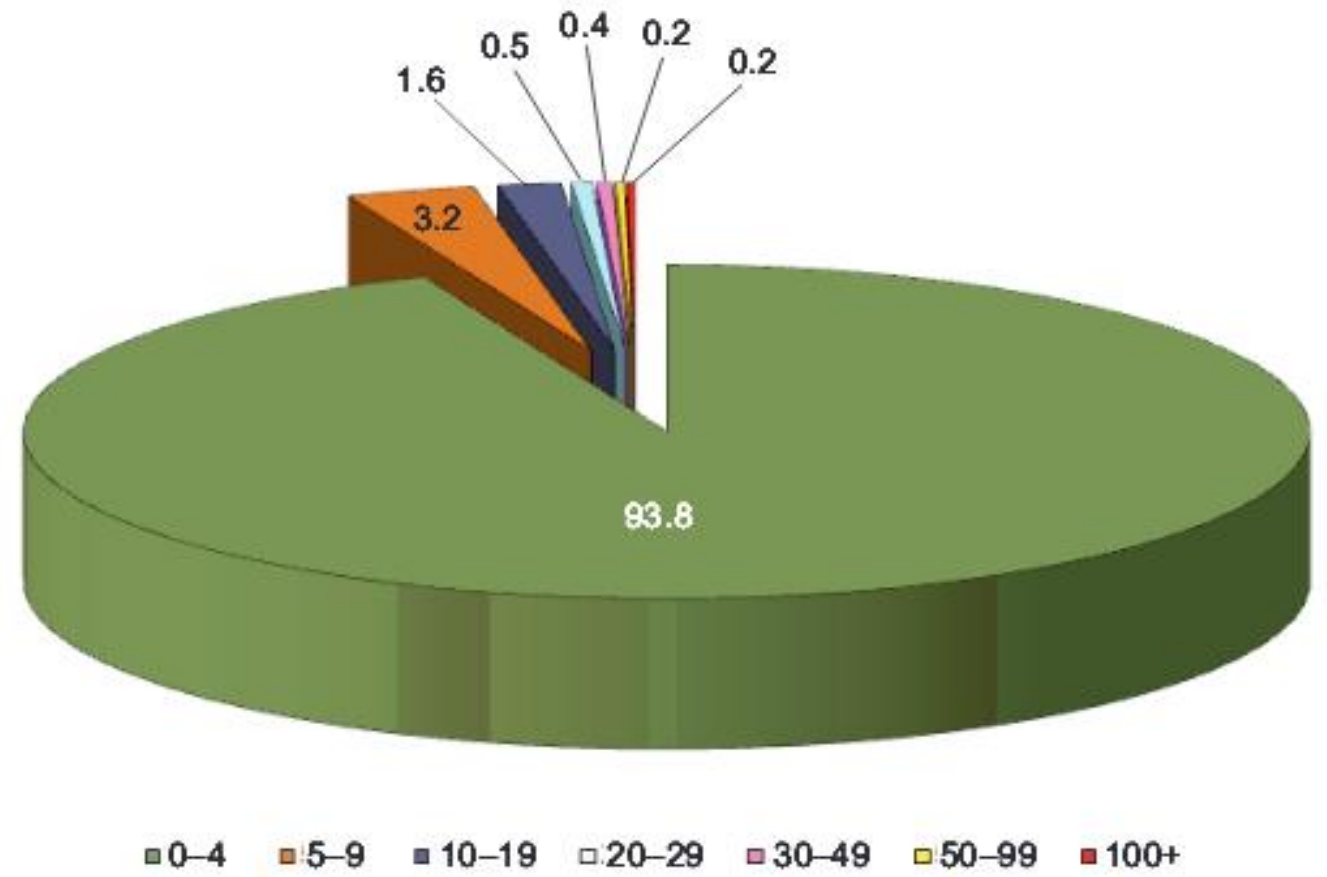

Figure 1: Share of Greek enterprises according to total number of employees (\%), 2006 (European Foundation for the Improvement of Living and Working Conditions, 2013).

As we can see at the "Annual report of EU SMEs, 2010/2011" (Wymenga et al., 2011), on the level of individual member states, there are three groups on the basis of individual growth rates of GVA ${ }^{1}$ and employment of SMEs in 2010:

1. The P-P $P^{2}$ COUNTRIES: Austria, Germany, Luxembourg, Malta, Romania, Sweden, UK. These countries have a positive growth rate of GVA and employment.

2. The N-N COUNTRIES: Greece, Ireland, Spain, Latvia, Lithuania. These countries have a negative growth rate in both categories.

\footnotetext{
${ }^{1}$ GVA: Gross Value Added (measures the contribution to an economy of an individual producer, industry, sector or region) (Financial Times lexicon.ft.com, n.d.)

${ }^{2}$ P-P stands for Positive-Positive,

$\mathrm{N}-\mathrm{N}$ stands for Negative-Negative,

P-N stands for Positive- Negative on the two discussed parameters, namely growth rate and employment.
} 
3. The P-N COUNTRIES: Belgium, Bulgaria, The Czech Republic, Denmark, Estonia, France, Italy, Cyprus, Hungary, Netherlands, Poland, Portugal, Slovenia, Slovakia, Finland. These countries have a positive growth rate in GVA and negative in employment.

Greece is a N-N country, which, can easily be depicted by the fact that 229,000 SMEs disappeared from the Greek market during the crisis years from 2008 till 2014, with a loss 700,000 employment positions (Mavipaßa, 2015).

Small and Medium Enterprises (SMEs) in Greece like all the other SMEs worldwide, facing several risks like interest rate risks, raw material prices risks, e- business and technological risks, supply chain risks, growth risks, management and employees risks (Falkner et. al., 2015). Additionally, they are also facing several financial risks like the risk that springs from the heavy taxation and the very long time needed for getting back the money which the Greek state owns to them from Value Added Tax (VAT) returns which sometimes is over 4 years (CNN.gr., 2016), not to mention the major problem of having little or even no access to bank finance. By strengthen their risk management mechanisms they can face successfully such risks and achieve sustainability and growth.

As uncertainty, requires planning, risk management comes to fill the gap of managing the downsides of uncertain outcomes (Farid, 2014). Risk management can be defined as a specific process which will be able to help the company to seek, eliminate and control risks, enhance benefits and avoid potential detriments from speculative exposure (Anderson et al., 2006, cited in Cuzdriorean, 2014). It can be very useful to SMEs by helping them identify potential risks that could jeopardize their success or even their very existence (Miller, 1992; Brustbauer, 2014; cited in Falkner et. al., 2015). According to Brustbauer (2016) the application of the right risk management mechanism can help SMEs to adjust to a changing environment, in order to gain strategic advantage in the long run.

\subsection{Problem and aim of the research}

The problem addressed by this study was that although family owned SMEs, which have less than 10 employees and operating in the retail sector in Greece in Thessaloniki area, use several kinds of risk management mechanisms, they find it difficult to overcome the financial risks they are facing, something which is underlined from the fact that almost 229,000 SMEs disappeared from the Greece's market during the crisis years from 2008 till 2014 (Mavipaßa, 2015).

The aim of this research is to unveil the financial impediments that prevent such risk management mechanisms to help SMEs overcome the financial risks they are facing.

\subsection{Research question}

"What are the financial impediments that interfere with the Greek SMEs' risk management mechanisms?"

The research question was investigated only on the basis of financial terms which spring from the Greek market's conditions, sales profits, economic measures posed by the Greek state, bank loans etc.

\section{SCIENTIFIC BASE}

This chapter describes the scientific base upon which the whole research was conducted in terms of the Greek SMEs' characteristics, their financial problems and the risk management mechanisms they are using.

\subsection{Greek SMEs and characteristics of the Greek case}

According to OECD, European Observatory for SMEs (1997, cited in Hyz, 2011) "the SME sector plays a very important role in today's economy. It is confirmed by the experience of highly developed countries, whose economies are dominated by the network of small (or very small) and medium-sized enterprises. The two most important measures of the role played by SMEs in the economy are: the share of this sector in the total number of economic unit and its ability to create new jobs", something which depicts the SMEs' importance for a country's economic model. In figure 2, we can see that the SME sector in Greece is more important than in the average European country (SBA ${ }^{3}$ Fact Sheet- Ireland, 2012, cited in Lacina et al., 2013).

\begin{tabular}{|c|c|c|c|c|c|c|c|c|c|}
\hline & \multicolumn{3}{|c|}{ Number of enterprises } & \multicolumn{3}{|c|}{ Employment } & \multicolumn{3}{|c|}{ Value added } \\
\hline & \multicolumn{2}{|c|}{ Greece } & \multirow{2}{*}{$\begin{array}{l}\text { EU27 } \\
\text { Share } \\
\text { (In\%) }\end{array}$} & \multicolumn{2}{|c|}{ Greece } & \multirow{2}{*}{$\begin{array}{l}\text { EU27 } \\
\text { Share } \\
\text { (In\%) }\end{array}$} & \multicolumn{2}{|c|}{ Greece } & \multirow{2}{*}{$\begin{array}{l}\text { EU27 } \\
\text { Share } \\
\text { (In \%) }\end{array}$} \\
\hline & Number & $\begin{array}{l}\text { Share } \\
\text { (In\%) }\end{array}$ & & Number & $\begin{array}{l}\text { Share } \\
\text { (In\%) }\end{array}$ & & Billi on $€$ & $\begin{array}{l}\text { Share } \\
\text { (In \%) }\end{array}$ & \\
\hline Micro & 703648 & 96.6 & 92.2 & 1338671 & 57.1 & 29.6 & 23 & 34.2 & 21.2 \\
\hline Small & 21586 & 3.0 & 6.5 & 404290 & 17.2 & 20.6 & 14 & 21.2 & 18.5 \\
\hline $\begin{array}{l}\text { Medium - } \\
\text { sized }\end{array}$ & 2649 & 0.4 & 1.1 & 255492 & 10.9 & 17.2 & 10 & 14.8 & 18.4 \\
\hline SMEs & $\mathbf{7 2 7 8 8 3}$ & 99.9 & 99.8 & 1998453 & 85.2 & 67.4 & 47 & 70.2 & 58.1 \\
\hline Large & 399 & 0.1 & 0.2 & 346200 & 14.8 & 32.6 & 20 & 29.8 & 41.9 \\
\hline Total & 728282 & 100 & 100 & 2344653 & 100 & 100 & 66 & 100 & 100 \\
\hline
\end{tabular}

\footnotetext{
3 SBA: Small Business Administration
} 
International Journal of Management and Information Technology Figure 2: SMEs in Greece. Basic figures (SBA Fact Sheet- Ireland, 2012, cited in Lacina et al., 2013).

Uncertainty seems to be a decisive factor for SMEs. According to Vlaar et al. (2006, cited in Giannacourou et al., 2014), when uncertainty increases, SMEs irrespective of size, tend to emphasize to processes and structures that point to more systematic task execution in order to minimize the error margin in decision making process. In the same direction are the remarks of Brouthers et al (2002, cited in Giannacourou et al., 2014) who underlined that SMEs are considered to have higher levels of uncertainty, especially among manufacturing firms due to larger resource commitment.

Courtney et al. (1997, pp.75-78, cited in Karaoulanis, 2015a) also refers to uncertainty by mentioning that there are four levels of uncertainty, a clear- enough future, alternate futures, a range of future, true ambiguity (Table 2).

Table 2: The four levels of uncertainty (Courtney et al., 1997, pp.75-78, cited in Karaoulanis, 2015a).

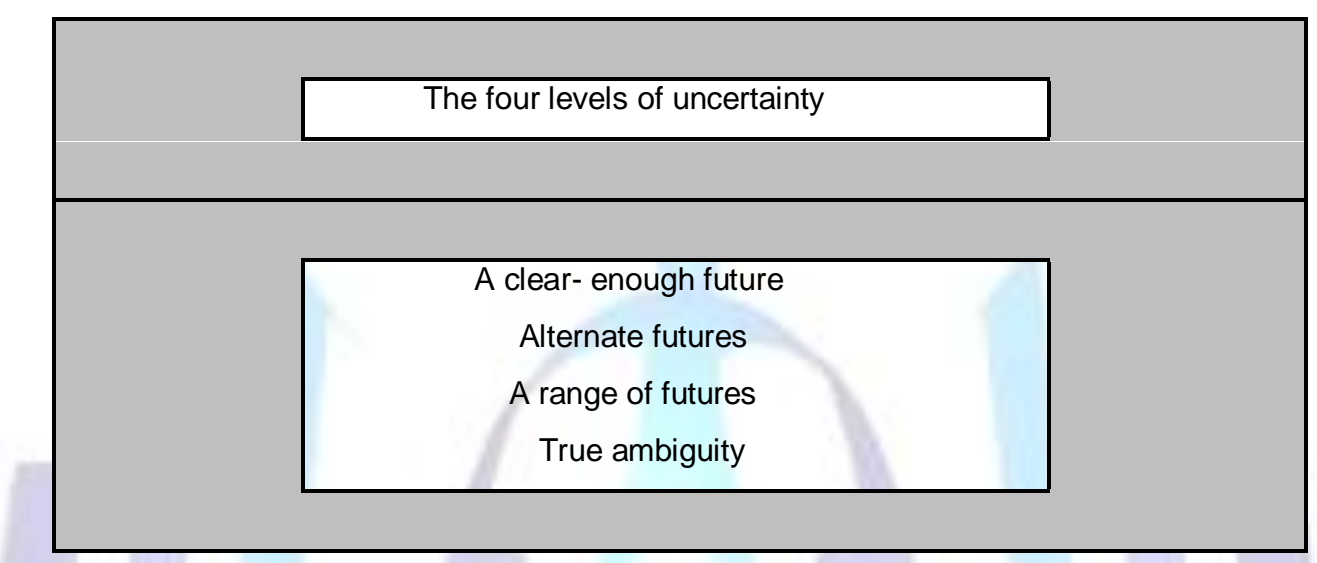

Although Greek SMEs are mainly facing the fourth category, which means that the interaction of multi dimension uncertainties create an impossible to predict future, it is not wise to throw up hands and act purely on gut instinct (Courtney et al., 1997, p.72, cited in Karaoulanis, 2015a). In that terms strategy implementation is a crucial factor for SMEs as the firm's strategy is one of the factors that consist the "nation's national diamonds" (Porter, 1990, cited in Karaoulanis, 2015b).

The mixture of recession and uncertainty that SMEs facing nowadays, makes their strategy implementation very difficult to be accomplished. Greek SMEs shouldn't adopt a "wait-and-see" strategy postponing large investments until the future becomes clear, because we don't know how long is going to take to be clear, while in the short run this kind of approach can create an opportunity window to existing and new competitors(Courtney et al., 1997, p.68, cited in Karaoulanis, 2015a).
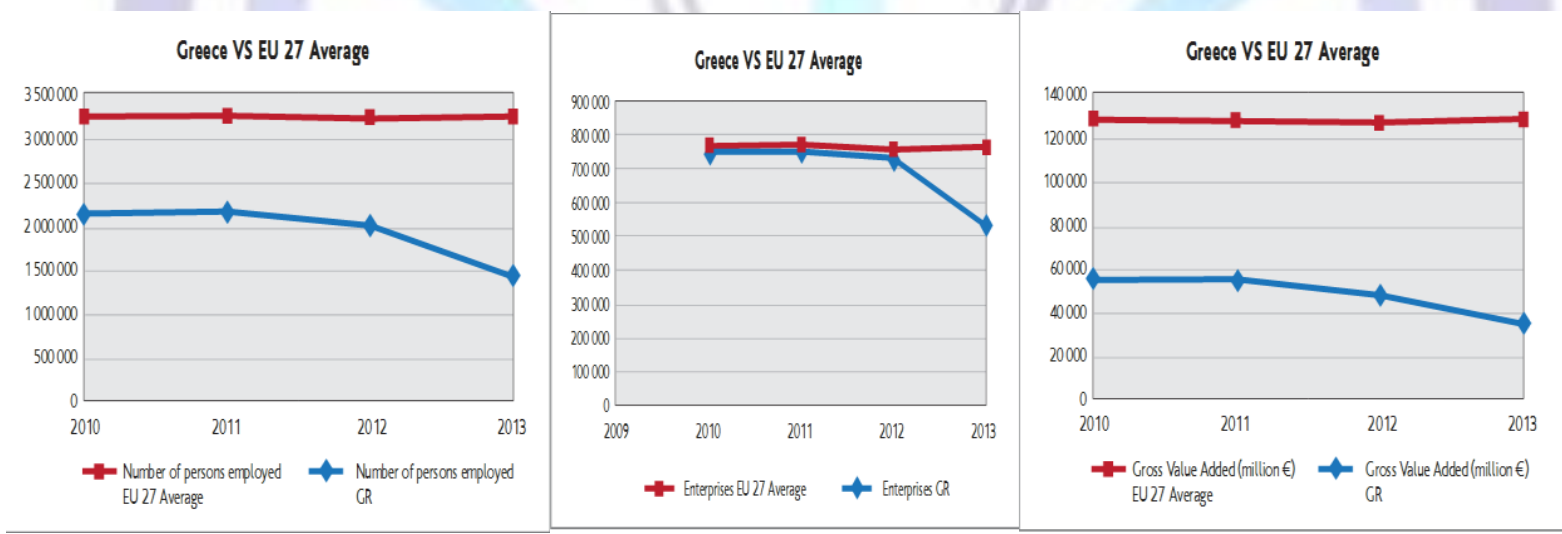

Figure 3: EU (27) average and respective data of Greece concerning the number, jobs and added value of SMEs during the period 2010-2013 (SBA fact sheet for Greece, 2010,2011,2012,2013, cited in GSEVEE ${ }^{5}$; ESEE ${ }^{6}$; KEEE $^{7}$;TFGR ${ }^{8}$;SETE $\left.{ }^{9}, 2014\right)$.

\footnotetext{
${ }^{4} \mathrm{~A}$ nation can create a national competitive advantage if it will obtain the following: firm strategy, structure and rivalry, demand conditions, related and supported industries, factor conditions (Porter, 1990, cited in Karaoulanis, 2015b).

${ }^{5}$ GSEVEE: Hellenic Confederation of Professionals, Craftsmen \& Merchants

${ }^{6}$ ESEE: National Confederation of Hellenic Commerce
} 


\subsection{Greek SMEs' financial problems}

Due to their importance as the backbone of the markets worldwide, financing SMEs was always a crucial topic for both academic and policy makers all over the world (Berger: Udell, 2006, cited in Zairis, 2015). In general SMEs worldwide can be described as financially frustrated as they are facing important difficulties in accessing formal finance in comparison with large companies (Zairis, 2015). The majority of them is mainly based on their internal finance (i.e. owner's capitals and/or loans and retained earnings) (Zairis, 2015).

Malkoutzis (2016) indicated that Greek SMEs have difficulties in gaining access to finance. In fact these difficulties are their major concern outweighing other concerns like regulation, competition, or finding customers. In juxtaposition, this concern was the least for similar companies in other EU countries. In Greece 31\% of SMEs has the above as their major concern while the same concern for the rest of the Europe was on an average of $10 \%$. It is indicative that Greek SMEs have difficulties in being financed by the Greek banks especially during the crisis years, as the Greek banks made the whole financing procedure very difficult, due to $r$ liquidity problems, by asking for collaterals and thby implementing complicated and time consuming financing procedures (Hyz, 2011).

There are significant evidence globally, that from all kinds of companies, SMEs in particular suffered from a significant credit crunch during the last big financial crisis (Carbó-Valverde et al., 2016). On the same wave length, the most important problem that a large number of SMEs facing nowadays in Greece, is to ensure their sustainability. Specific loan programmes especially for SMEs could have been very handy in helping them to reduce the current loan's cost which is high (between 9-11\%) $\left(\mathrm{HBA}^{10}, 2013\right)$.

In contemporary Greece, SMEs, in terms of liquidity, have to deal not only with the capital controls imposed from June 2015, but also with the political uncertainty. According to the National Bank of Greece (NBG) (2016) report, political uncertainty and capital controls led Greek SMEs to a decline in sales during the third quarter of 2015 (just after the capital controls implementation) of $15 \%$ compared with the $4 \%$ during the second quarter of the same year, while for the micro enterprises this decline have reached the $23 \%$ and $10 \%$ respectively. Also, the report indicates that the impact was much bigger in SMEs than in larger companies in the same third quarter of 2015 (NBG, 2016).

Another important risk factor for Greek SMEs is according to Chrysopoulos (2016) that SMEs taxation is at $29 \%$, while they have to pay additionally a flat rate of 1,000 euros tax per year regardless of revenues. Greek economic analysts say that this will mathematically lead many SMEs to extinction or to become tax exiles and move to neighbouring countries such as Bulgaria where the tax on business is as low as 10\% (Chrysopoulos, 2016). As a result of the heavy taxation and the whole negative economic climate, Greek SMEs tend to cultivate a negative tax compliance behaviour. According to Kaplanoglou et al., (2016), such behaviour implies strong connections between the quality of political and of tax institutions, while trust between SMEs and the state seem to play a very important role in increasing intended compliance and in deterring strategic tax evasion.

\subsection{Risk management and SMEs}

Defining risk is a quite controversial issue as many definitions can be found in the bibliography. According to Aven (2012), risk has three possible definitions, which are the following: 1. Exposure to the possibility of loss, damage, injury or to some other adverse or unwelcomed, thus negative circumstances, 2. A hazardous journey, or a course of action; a venture, 3. A person or thing regarded as likely to produce a good or bad outcome in a particular respect; a person or a thing which could be regarded as a threat or as a potential source of danger.

The five major steps of the risk process in SMEs are, according to Hollman and Mohamad-Zadeh (1984, cited in Falkner et al., 2015), to identify risks, to analyse risks, to select techniques, to implement strategy, to control. The risk management process involves the following steps (NSW ${ }^{11}$ Department of State and Regional Department Small Business Development Division, 2005) as depicted in figure 4.

\footnotetext{
${ }^{7}$ KEEE: Union of Hellenic Chambers of Commerce

8 TFGR: Task Force for Greece of the European Commission

${ }^{9}$ SETE: Association of Greek Tourist enterprises

${ }^{10}$ HBA: Hellenic Banks Association

${ }^{11}$ NSW: New South Wales
} 


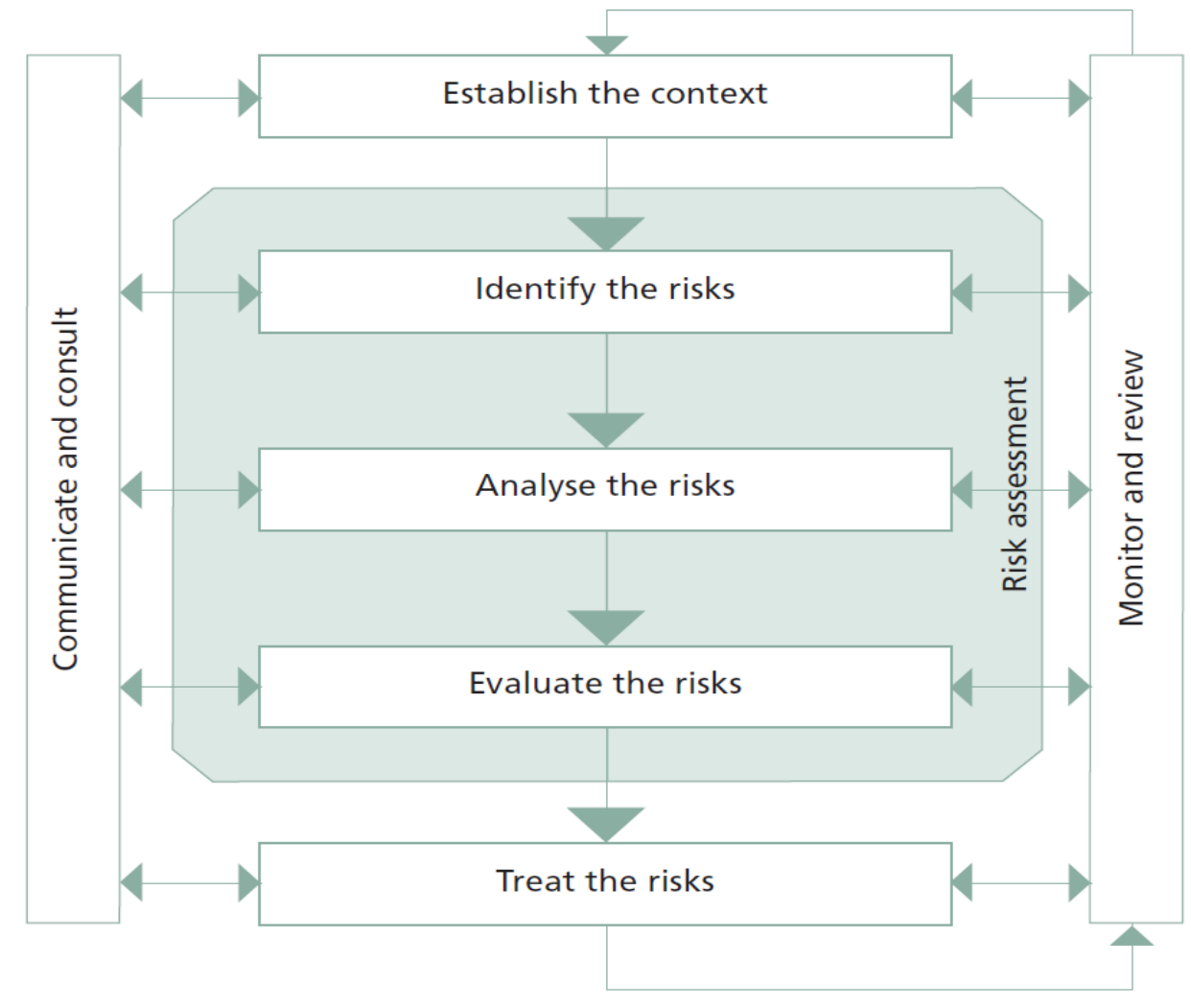

Figure 4: Risk Management Process (NSW Department of State and Regional Department Small Business Development Division, 2005).

According to Colier et al. (2007, cited in Cuzdriorean, 2014), the objective of risk management is to maximise the potential of success and accordingly to minimize the probability of potential future loss. As a result, risk management can be seen as the cornerstone of the good corporate governance. NSW Department of State and Regional Department of Small Business Development Division (2005), indicated that an emerging concept in risk management is that there are three types of risk, namely, opportunity based risk, uncertainty based risk and hazard based risk (Figure 5).

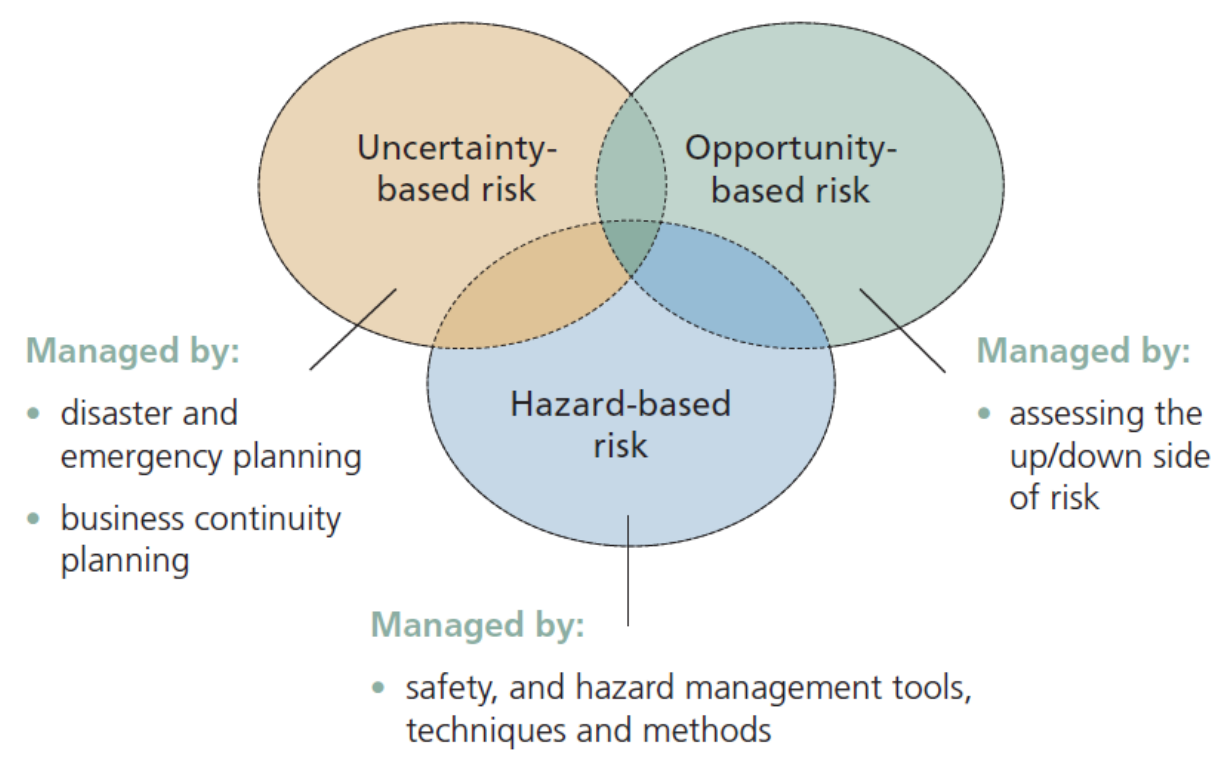

Figure 5: The three types of risk and how they are managed (NSW Department of State and Regional Development, 2005). 

Every business, thus SMEs too, that want to manage financial risk need to have the right financial management approach. Such financial management need to be transparent and effective in order to maximize income. It needs to be able to determine the right pricing for a product or service, to minimize and manage the expenses, such as bills and correct wages paid on time and to ensure that creditors will honour their accounts. Financial management is also about determining where both financial risks and opportunities will be handled efficiently and effective (NSW Department of State and Regional Development, 2005).

Jindrichovska (2013) stated that there are three elements of financial management, which are (1) liquidity and cash flow management, (2) long- term asset acquisition, (3) funding, capital structure and cost of funding. In SMEs, the most important of these elements is the liquidity and cash flow management (Jindrichovska, 2013), something which is even more important in recession situations like the ones SMEs are facing in Greece nowadays.

Another important parameter of risk management is "risk appetite". As Harwood et al. (2009, cited in Georgousopoulou et al., 2014), stated, the overall risk propensity of an organization, represents the amount of risk that this specific organization is willing to justify and tolerate and is called "risk appetite". The risk appetite changes through time as market uncertainty changes (Gai et al., 2006, cited in Georgousopoulou, 2014).

It is important here to underline that the economic behaviour is usually influenced by the perception of the decision makers. Of course such behaviour is influenced by the social- economic characteristics and the structure of the assets of their companies (Borges et al., 2012).

According to Hubbard (2009), the risk management success/ failure spectrum comprises of the following levels:

$\checkmark$ BEST: According to that level, the company builds quantitative models in order to run simulations. With the right use of risk models which can validate all inputs via proven statistical methods, the modellers check against reality in a sceptical way and try to improve their risk models thru their efforts to systematically identify all risks in the firm (Hubbard, 2009).

$\checkmark$ BETTER: Managers build quantitative models by the use of at least some proven components. In such way, the scope of risk management expands in order to include more of the risks (Hubbard, 2009).

$\checkmark$ BASELINE: Managers use their intuition in order to access the risks in question and to implement any mitigation strategies that are available. In such level, no formal risk management is attempted (Hubbard, 2009).

$\checkmark$ WORSE: The methods used are usually called as "soft" or "scoring" methods. Sometimes they even can be misapplied quantitative methods. This level may be no worse than the previous one, except that companies waste more time and money (Hubbard, 2009).

$\checkmark$ WORST: In this level, although managers use ineffective methods, they have great confidence in them although they can usually add error to the risk evaluation. Although such methods might be quite sophisticated, they can cause erroneous decisions, which would have been avoided if no method at all have been used (Hubbard, 2009).

\section{METHODOLOGY}

There are several strategies in terms of methodology, like survey, case study, experiments, ethnography, phenomenology, grounded theory, action research and mixed methods (Denscombe, 2010).

Experiments are meant to be used in order to help the researcher undertake an empirical investigation under controlled conditions designed to outline the relationships between specific factors. Such approach had nothing to do with this specific research which aimed to investigate a phenomenon on a specific point of time (Denscombe, 2010).

Ethnography (Malinowski, 1992, cited in Denscombe, 2010), deals with the totality of all social, cultural and psychological aspects of the community, something which was not feasible and out of the scope of such a research project due to its focus and time and budget limitations.

Phenomenology is basically associated with description and no analysis (Denscombe, 2010, p.103), something which was in contrast to the nature of this research which want to shed some light to an everyday problem by analysing the findings.

Grounded theory, although it is very strongly connected with qualitative analysis, had several problems, like the lack of a precise planning as it is difficult to predict from the beginning the nature of the sample, or the danger that the theory generated from the data might ignore the influence of social- economic and political factors, or the complexity in analysis (Denscombe, 2010). On the contrary, this research intended to focus on social- economic factors, not to mention the time and budget limitations which were a crucial coefficient and made a complex analysis to be a bad fit.

Action research strategy involves the integration of research with practice thus an extra heavy work load for the practitioners (Denscombe, 2010, p.135), which was out of the scope of this research which didn't have such time convenience.

Mixed methods are a more complex strategy, thus was also not a good fit due to time and size limitations of this research project. 

The case study methodology, is a very good approach in terms of trying to illuminate a decision or a set of decisions, why they were taken, how they were implemented and with what result (Schramm, 1971, cited in Yin, 2014, p.15). The researcher didn't choose it because although a case study uses a case (i.e. a company) and investigates several aspects in question on a very deep level, it was questionable if such a methodology would serve the research project adequately, as by studying just one case we wouldn't be able to unveil all the whole problem's dimensions, no matter how deep we were able to dig. The possibility of using a multiple case study methodology was rejected from the beginning due to the magnitude of such research.

On the other hand, by selecting a wide range of companies from different industries i.e. food and beverage, clothes, pharmacies etc., while using the survey approach, the researcher accomplished a more holistic view of the problem and finally was able to dig deeper into finding answers to the research question.

Other reason for choosing the survey methodology was that the researcher wanted to focus at a specific point in time (Denscombe, 2010), which was the recession years in contemporary Greece. The researcher also, implemented an empirical research as he had to "get out of the chair" (Denscombe, 2010, p.12) and reach several companies.

Finally, the researcher, in order to achieve the best possible outcome in terms of how many companies to reach, used a combination of face-to-face surveys, and internet surveys (Denscombe, 2010, pp.12-17). A prior notice approach was used in order to create the basis upon which a good response rate was achieved (Denscombe, 2010, pp.20). As the researcher was familiar with the companies' managers and culture, all the companies that were approached, were companies where free speech was a prerequisite in order to assure the unbiased response to the questionnaires posed. Anonymity was a big plus in achieving high response rates, while the number of the sample companies was 15.

\section{Data collection methods}

The questionnaires method was used as the most appropriate one, as it dealt in an excellent way with the research's goals to get standardized data from identical questions and because what was required was straightforward informationrelatively brief and uncontroversial (Denscombe, 2010, p.156). Questionnaires were more suitable than interviews as it was quite difficult and time consuming to arrange interviews with so many managers who had very tight time schedules. The researcher also chose the questionnaires method in order to eliminate potential personal bias as he didn't involve in the questions/ responses process at all, while the respondents provided straight forward answers via the open ended questions. Also, although the respondents were operating in the Thessaloniki area or near it, the distance to some of them was, in some occasions, even 40 kilometres, something which made the interviews to look very costly and time consuming comparing to the email questionnaires.

This research used the internet questionnaires (Denscombe, 2010, p.159) and especially the "questionnaires sent as an attachment to an email" or "web based questionnaires" (Denscombe, 2010, p.159, cited in Karaoulanis, 2017, p. 7475), because they were very user friendly, had a very good looking interface and the researcher was able to attach to the emails the informed consent form. The e- mail questionnaires were rejected due to the not attracting interface and the large number of information included in the body of the e- mail, something which made them inconvenient to handle from the respondents.

Only open ended questions were used as the research followed a qualitative direction. Such questions were adapted because they provided a clear path to the respondent in order to reflect the full richness and complexity of her views (Denscombe, 2010, p.165), thus helped the researcher to dig deeper into the problem and answer the research question in a coherent and efficient way. Closed questions were avoided in order to eliminate possible bias as closed questions can drive the respondents to a specific path, by allowing only answers that fit into specific categories (Denscombe, 2010, p.166).

The questions used in the questionnaires were chosen on the basis of targeting to get answers to the research questions. SMEs' owners were asked about their risk management mechanisms in order to determine if they use any, what kind and at what extend. The respondents also were asked to answer to questions regarding factors that generate financial risks, about their financial problems and their connection to the general Greek financial climate in order to be determined the whole frame into which the SMEs in question operate. Finally, the respondents answered questions regarding the connection their risk management mechanisms have with the financial impediments they are facing in order to determine if such connection exist and which are its implication to such mechanisms.

Official papers, data bases and state or EU reports were gathered by the researcher in order to help him acquire a spherical knowledge of the subject in question.

The researcher had to translate the questionnaires into Greek as he wanted to make them more convenient to the respondents in order to increase the response rate.

\section{Data Collection Strategy}

This research was based on an exploratory sample and not on a representative one because it was a small scale research and the researcher from the beginning aimed to do a qualitative research. Also, this kind of sample is more useful when there is a need to gather new insights, as in our case. The representative sample technique is more focused on quantitative researches and larger surveys (Denscombe, 2010, p.24). 

The researcher chose the cluster sampling technique as it was the most appropriate for this specific research. Due to budget limitations, the researcher needed to use this technique in order to save time and money. The cluster sampling approach was used because the cluster was a pre-existing one (the SMEs in Greece). Also, each sub- cluster (pharmacies, food and beverage stores, hardware stores etc.) reflected the heterogeneity of the population in the specific cluster (SMEs in the retail sector), at least in a good degree (Denscombe, 2010, p.29).

The cluster sampling approach was chosen over the random sampling and the systematic sampling because the systematic approach was not suitable for the project as according to this technique, one has to pick every $\mathrm{n}^{\text {th }}$ item from an appropriate list (Denscombe, 2010, p.28). This was not suitable as it required a very large sample, something which was very difficult to be achieved for such scale research.

The random sampling approach involves three parameters, a known population from which the sample would be taken, a sampling frame which provides a list of all the items in the population and allows them to be picked by the use of a unique identifier and a process of random selection which usually involves a random number generator, something which usually needs the usage of a specific software (Denscombe, 2010, pp.27,28). Such technique would have created problems to the researcher as he couldn't find a list of all the items in the population and also, the researcher did not know the exact number of SMEs in the area and where they exist (Denscombe, 2010, p.27, 28). Also the acquisition of the proper software was denoting extra time and cost.

The researcher valued his data during the data analysis process in terms of its saturation (in what degree the gathered data was repeated). Data saturation is a very controversial issue, and quite abstract, as there is no specific rule in the international bibliography (Bowen, 2008). Reaching the right level of data saturation in order to achieve a very wellgrounded qualitative result is a very difficult task (O' Reilly et al., 2013). The researcher adapted arbitrarily a value saturation index of $80 \%$. This threshold was appointed due to the small size and time restriction issues that arose during this research and was reached only once.

\section{Data analysis}

The qualitative approach was used instead of the quantitative one, mainly because this was a small scale research (Denscombe, 2010, p.238) and we tried to achieve a holistic perspective of the questions in hand, while the quantitative approach mainly has to be associated with large- scale studies and tend to analyse specific variables(Denscombe, 2010, p.238). The qualitative approach was chosen because both the data and the analysis in such approach, have their roots in the conditions of social existence, as the research was implemented in the field and not on any "armchair" (Denscombe, 2010, p.304). The researcher needed richness and detail to the data (Denscombe, 2010, p.304) in order to reach as deep as possible.

Although the quantitative approach had several advantages, its very nature prohibited the researcher from adapting it. More specifically, the researcher didn't want to present numbers of something as he was convinced that such approach wouldn't have helped him to identify the problem in hand. What was needed for this project was to specifically identify the impediments in question by presenting the whole situation Greek SMEs are facing in contemporary Greece.

The original data was protected from the beginning as the researcher created several back- ups. One back up on his computer's desktop, one back- up on an external hard disc and another one on a memory stick.

The analysis followed the inductive path, which means that the researcher followed the road from the particular to the general in order to achieve more generalized statements about the topic (Denscombe, 2010, p.273). Following that pattern, the researcher analyzed the data gathered in order to reach to a generalization that sprung from the particular cases that depicted in it (Karaoulanis, 2017).

The researcher followed five main stages in data analysis, which were the following (Denscombe, 2010): 1. The data was catalogued and indexed. The researcher created indexes like i.e. $C$ for a clothes store, $P$ for pharmacies, $M$ for mini markets etc. 2. The researcher looked for obvious recurrent themes and issues. He added memos and notes on the data, like "company operating on a neighborhood basis" or "company with 3 employees" etc. 3 . The researcher coded the data. The whole procedure followed a specific pattern (Denscombe, 2010, p.240, cited in Karaoulanis, 2017), according to which, we had the codes categorizing, reduction of number of codes and categories in order to create a more easy to use number of codes and categories, hierarchy development of both codes and categories and finally the check of the emerging codes, categories and concepts with the data.

4. The researcher presented his written interpretation of the findings (Denscombe, 2010, p.240). Several quotes were used in order to help the reader get a thorough view of what was found in the field. The researcher used some visualization tools from the Dedoose software in order to illustrate his findings. 5 . The researcher compared the findings to alternative explanations from the bibliography in order to understand their congruence or disagreement with the existing literature.

This research was assisted by what is mentioned in Denscombe (2010, p.278) as CAQDAS (Computer Assisted Qualitative Data Analysis) tool which is represented here by the Dedoose software, via which the researcher did the coding and connected its responses to specific codes and created a net of data.

The research was performed from 20 of January 2017 until the $25^{\text {th }}$ of April 2017 in Greece. 


\section{Research ethics}

The research followed the three meanings of professional ethics as described in the Swedish Science Council's (SSC) guidelines (Codex, n.d.). The research preformed "good science", it followed all national and local rules, it didn't provoke any discrimination or humiliation issues and the researcher had an excellent behaviour throughout the whole research process. The researcher acted in compliance with the professional ethic codes as described by the SSC in the Codex site for each profession.

According to Denscombe (2010, p.331), social researchers have to protect the interests of the respondents and to ensure via the provided consent form the voluntarily basis of their participation. In our case an informed consent form was disseminated, accompanying the questionnaires, which was very descriptive on what this research was about including the communication elements of the researcher. All emails and written questionnaires were permanently deleted and destroyed after the process. Of course in terms of the e- mail questionnaires one can argue that security issues could arise as the researcher has in possession the respondents' email address, but this is a general disadvantage of the internet questionnaires anyway.

All the extracted data was stored in several places, in electronic and physical form, and indexed without names or any other details, like addresses etc. Finally, no confidential questions of any kind were asked to the respondents like their age, marital status, ethnic background etc.

\section{RESULTS}

In this part, the results of this survey will be presented in an analytical way.

\section{Data collection and analysis}

The data preparation plan, in qualitative analysis, includes the cataloguing of the text, the preparation of the data and its loading onto the chosen software and finally, the transcribing of the available text (Denscombe, 2010, p.240).

The data was gathered via the use of e-mail questionnaires and questionnaires which the researcher handed personally to the respondents when they didn't have the time to answer remotely and his presence needed. The whole procedure of the data gathering lasted about twelve days. It started on the $1^{\text {st }}$ of March 2017 and concluded on the $13^{\text {th }}$ of the same month.

Each questionnaire was catalogued by indexing it by a serial number (i.e. 1FB3 where 1 is the number, FB stands for Food and beverage and 3 the number of personnel) as the researcher tried to handle the whole process in a way that he would have been able to know every single moment what was needed in terms of actions to be taken.

One important point of the whole procedure was that the researcher had to deliver his questionnaires into Greek because almost all of the respondents kindly denied to answer them in English.

After the data gathering, the researcher categorised the responses, according to the questions posed and then subcategorised them according to the trends that the responses created. For example, the responses to the question $5 \mathrm{a}$ created some trends which defined the risk management mechanisms each company uses, i.e. liquidity and cash flow management, disaster an emergency planning etc. In that way, it was easy enough to distinguish the different trends which the responses created.

After the data was categorised, was loaded onto the Dedoose software in order to get the qualitative results needed. The researcher attached a memo (figure 6 ) to each questionnaire in order to give some info about the specific response. For example, a simplified memo was to write in it the number of employees of the company etc. Continuing, the researcher had to create the codes (figure 7). 


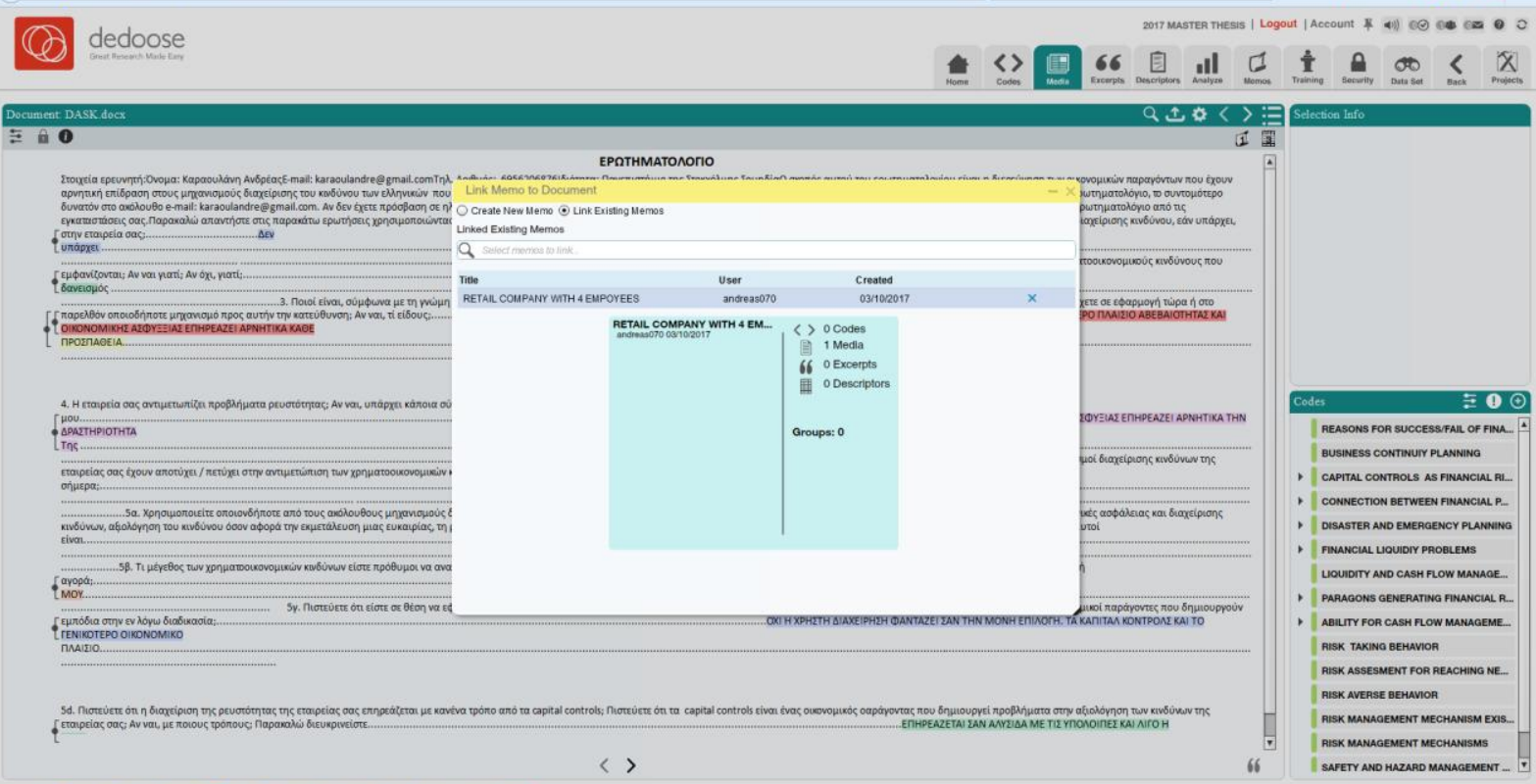

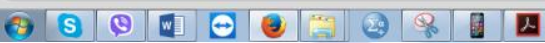

Figure 6: Memo attached to a questionnaire (Dedoose software)

29 codes were created in order to be able to categorise all the answers to the questionnaires. The researcher matched each excerpt from the responses to the codes that were created. The next step included the creation of the descriptors. 17 descriptors were created and linked to the questionnaires. The analysis was achieved by synthesizing the separate data elements and distinguish the trends and connections between them.

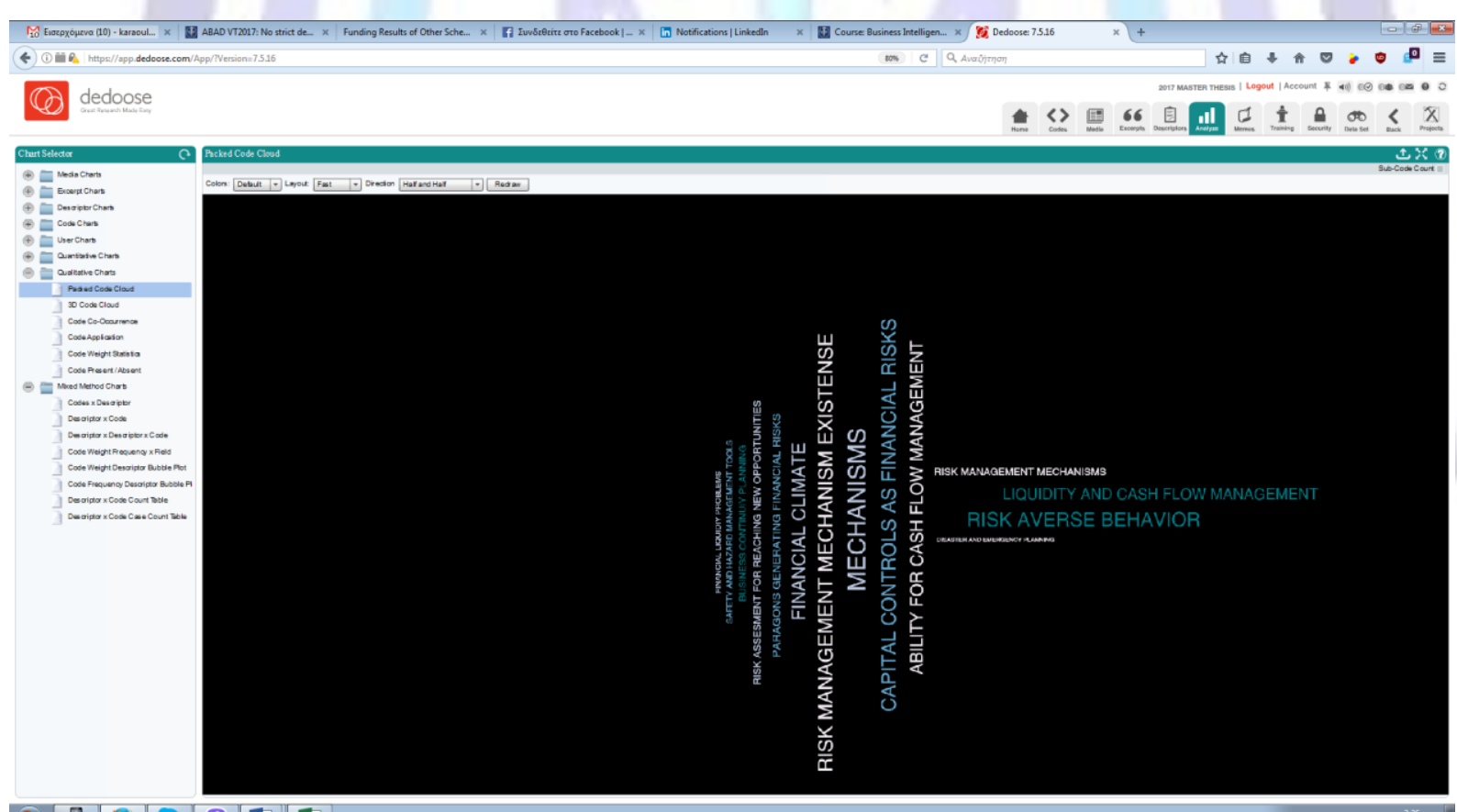

(9)

Figure 7: Packed Dedoose code cloud

A sample of the Dedoose analysis process can be seen in brief in the snapshots provided in appendix $\mathrm{C}$.

\section{Results presentation}

Several trends were found from the responses to the questionnaires. In the following paragraphs such trends will be presented. 


\section{Risk management mechanisms}

In terms of the potential risk management process that each company may used, the big majority of the respondents answered that there wasn't any kind of official risk management process in their company, mainly due to its size and the fact that they couldn't afford to implement such processes. On the other hand, the big majority added that they use some kind of informal risk management processes without the use of any software or a separate department. Some of these informal processes/ mechanisms were the forecasting of their customers' consumeristic behavior, budget forecasting, the creation of procurement plans according to the fluctuations in the USD or GBP ${ }^{12}$ difference from the Euro, the effort to hold the prices as low as possible and establishment of a friendly customer policy in terms of selling goods and get paid later. Also, some companies replied that they were trying to eliminate wastes in terms of procurement by being as lean as possible. Some managers replied that they were trying to eliminate the aftermath of such issues by contacting a very strict analysis of their inventory and eliminate wastes..

As we can see the main trend was that almost everybody had only informal risk management mechanisms. On the other hand, it is remarkable that many managers although they were using such informal mechanisms they didn't realize that. As a result they answered that they didn't use such mechanisms, while in the next questions about which mechanisms they used, they answered that they use i.e. cash flow management. This is indicative of why Greek SMEs, according to the Hubbard's (2009) scale, are at the "baseline" and "worst" level and why managers use more their intuition.

The big majority of the respondents stated that their risk management mechanisms, formal or infrormal succeeded till now in terms of how they handled their financial risks. This success, on the other hand, was only on the basis of sustainability. Expantion was out of the question for all the respondents due to the overall financial climate of the country.

On the antipode some respondents argued that their mechanisms failed. The reasons were that due to the unstable and unpredictable climate in the Greek market it is impossible to predict or to restrain things. Also, they argued that "we cannot predict or create models describing the consuming behavior of our customers, because this is something that changes from day to day due to the unstable political and financial climate" as they quoted.

It is questionnable if the ones that argued that their mechanisms failed really understood the meaning of the question, as from their responses, it is possible that they perceive the failure in terms of growth. If that was the case, then they are in accordance with the ones who said that their mechanisms succeed as they were actually saying that their success was only on the basis of sustainability and not of growth.

In terms of which of the suggested risk management mechanisms the companies use, the answers gathered indicated that many companies had some kind of insurance (i.e. fire or theft insurance etc.), all the companies had some kind of liquidity and cash flow management, while the majority of the companies said that they use some kind of a business continuity planning for the next 6-12 months. There were only a few answers indicating that they dont use any of the suggested mechanisms and only one that they use some kind of a software (Microsoft Excel).

Some specific companies (pharmacies) were facing different kind of problems comparing to the other ones (food and beverage, furniture etc.), which had to do with the drug procurement and supply. This is why such companies had to create informal stock mechanisms while they had to deal with the potential lack of drugs' supply due to i.e. capital controls etc. For example, one pharmacy owner argued the valorization of the products comes directly from the ministry of commerce, thus he couldn't intervene with the prices. This heterogeneity inside the same sub- cluster (retail SMEs) is important as it depicts the different trends between companies which are facing similar problems.

Table 3: The main risk management mechanisms which the companies use

\begin{tabular}{|c|}
\hline Risk management mechanisms \\
\hline Insurance \\
\hline Liquidity management \\
\hline Cash management \\
\hline Safety and hazard management tools \\
\hline Supply management \\
\hline Stock management mechanisms \\
\hline Risk assessment for reaching new opportunities
\end{tabular}

The vast majority of the respondents argued that in the near future they are not able to implement any liquidity or cash flow management formal mechanisms due to the fact that they don't have the budget needed for such implementation and because they manage things quite well till now (with their informal ones). Responses like " $i$ am just fine", or " $i$ am dealing

\footnotetext{
12 USD: United States Dollar

GBP: British Pound
} 
International Journal of Management and Information Technology with my cash management very well till now, so why to change anything" were indicative of this trend. This kind of responces indicate a pessimistic approach of the near future, as they depict the owners' bad forecasting in terms of growth.

\section{Financial impediments}

In terms of whether the company in question managed to face succesfully its financial risks, all of the respondents answered that they did, but only temporarily, as the overall Greek market's conditions weren't stable. The big majority of the respondents answered that they managed to face successfuly the financial risks because they don't have any loans from previous years to pay. Some respondents argued that "sometimes i have to reject business proposals which i believe are of high risk" as they quoted. Some others stated that they are handling very carefully the procurement part of their business and their overall cash flow because mistakes are very difficult, to be corrected under the specific social-economic situation.

Table 4: Main answers in "reasons for successful facing of the company's financial risks" question

\begin{tabular}{|c|}
\hline Main reasons why the company faces successfully its financial risks \\
\hline "Yes till now, but things getting tougher by the time due the market situation" \\
\hline "Yes till now, although I have problems due to previous loans that running" \\
\hline "Because I don't have any loans to pay" \\
\hline "Because we have insured the company and we don't take high risk jobs" \\
\hline "Because we are very careful in budget management and we do not pursue any loans" \\
\hline "Because I have an extroversion strategy" \\
\hline "Because my company did not affect till now from the financial crisis, due to its nature" \\
\hline "Because we do an efficient and conservative budgeting"
\end{tabular}

Regarding the reasons that generate financial risks, the major trends showed that they were the lack of liquidity, mainly due to the fact that banks reduced dramatically the SMEs' financing, the unstable political climate, the capital controls, the reduced consuming power of the Greek consumers. In few cases, we had the response that a big problem is the difference between the Euro and the Dollar or British Pound (table 4).

Table 5: Main answers in "reasons generating financial risks" question

\begin{tabular}{|c|}
\hline Reasons generating financial risks \\
\hline "Lack of liquidity due to the banks' policy to reduce financing" \\
\hline "Unstable political climate" \\
\hline "Capital controls" \\
\hline "Reduced consuming power from their customers" \\
\hline "Difference in price between Euro and GBP and/or USD" \\
\hline
\end{tabular}

The big majority of the companies answered that they are facing several financial problems and that these problems were all strictly connected to the financial climate. The main financial problems were the lack of liquidity, as the banks "are not willing to give any kind of entreprenerial loan" as they quoted, their reduced turnover, the increase in the products' prices and previous years' loans. Very few of respondents answered that they did not face any kind of financial problems. Quotes like "of course i face financial problems" or " yes we face such problems, mainly due to the reduced turnover which is strongly related to the reduced consuming ability of my customers" are quite representative of the whole picture. Another trend was that they face financial problems because they could not use checks for payments anymore as " nobody trusts nobody anymore" as they quoted. 
International Journal of Management and Information Technology Table 6: Main answers in "financial problems" they face question

\begin{tabular}{|c|}
\hline Main financial problems \\
\hline "Liquidity problems" \\
\hline "Reduced turnover" \\
\hline "Continuous increase in products' prices" \\
\hline "Loans from previous years" \\
\hline "Can't use checks for payments" \\
\hline
\end{tabular}

The amount of financial risk that the companies were willing to undertake had a catholic response, as all replied that they were not willing to take any amount of risk due to the financial and political climate the country faces.

In terms of which financial impediments prevent their formal or informal risk management mechanisms to help them with their business, the findings indicated that such impediments were the capital controls which lowering the customers' buying behavior, the growing decrease in their customers' wages which contributes to the same direction, the uncertaint Greek market, the unstable political scenery and the liquidity problem which is strongly connected with the enormous reduce in bank lending and the capital controls.

Table 7:Main answers in "financial impediments to risk management mechanisms" question

\begin{tabular}{|c|}
\hline Main financial impediments to risk management mechanisms \\
\hline "Capital controls" \\
\hline "Decrease in consumeristic ability" \\
\hline "Market uncertainty" \\
\hline "Unstable political scenery" \\
"Liquidity problems " \\
\hline
\end{tabular}

In terms of the capital controls, all respondents agreed that they are a strong risk generating influencer which strongly affects their liquidity management.

The majority of their suppliers accept for payment only cash or bank wire, instead of postdated checks something which creates liquidity problems as cash is difficult to find due to the capital controls. They also argued that after the capital controls their customers' behavior has shaped negatively because they are not willing to spend their money in the way they used to due to the lack of cash. This is combination with the customers' unwillingness to use plastic money creates some liquidity problems.

\section{DISCUSSION}

In this part, the results of this research project will be discussed.

\section{Main findings}

The main findings of this research indicated that the financial impediments that interfere with the risk management mechanisms were the general unstable financial climate which disables the prediction of the consumeristic behaviour of the companies' customers, the political unstable climate which couldn't help them predict their future moves in terms of how to deal with their risks, the capital controls which create liquidity problems and that the SMEs that were questioned had limited access to bank financing. Such impediments did not let, even their informal risk management mechanisms, to help the companies because they couldn't predict future trends and patterns due to the unpredictable and unstable environment. Also, such mechanisms sometimes seemed to be unusefull because they couldn't prevent, i.e. the liquidity problems which spring from directions which cannot be seized (i.e if the country will achieve the EU agreement for financing, new taxation laws which capsize any financial planning etc.).

Another important finding was that almost all of the companies didn't have any formal risk management mechanisms, although they use them, mainly in an informal, non sofisticated, way.

The most impressive main finding of this research was that SMEs' owners that were questionned weren't willing to take any kind of risk. They were risk averse due to the whole country's financial climate.

Also from the responses we can see a correlation between liquidity management, cash flow management, risk assesment for reaching new opportunities and safety / hazard management with business continuity planning, something which might mean that such risk management mechanisms were used as part of the overall business continuity planning process. 


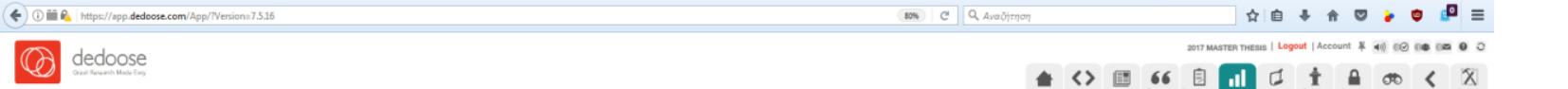

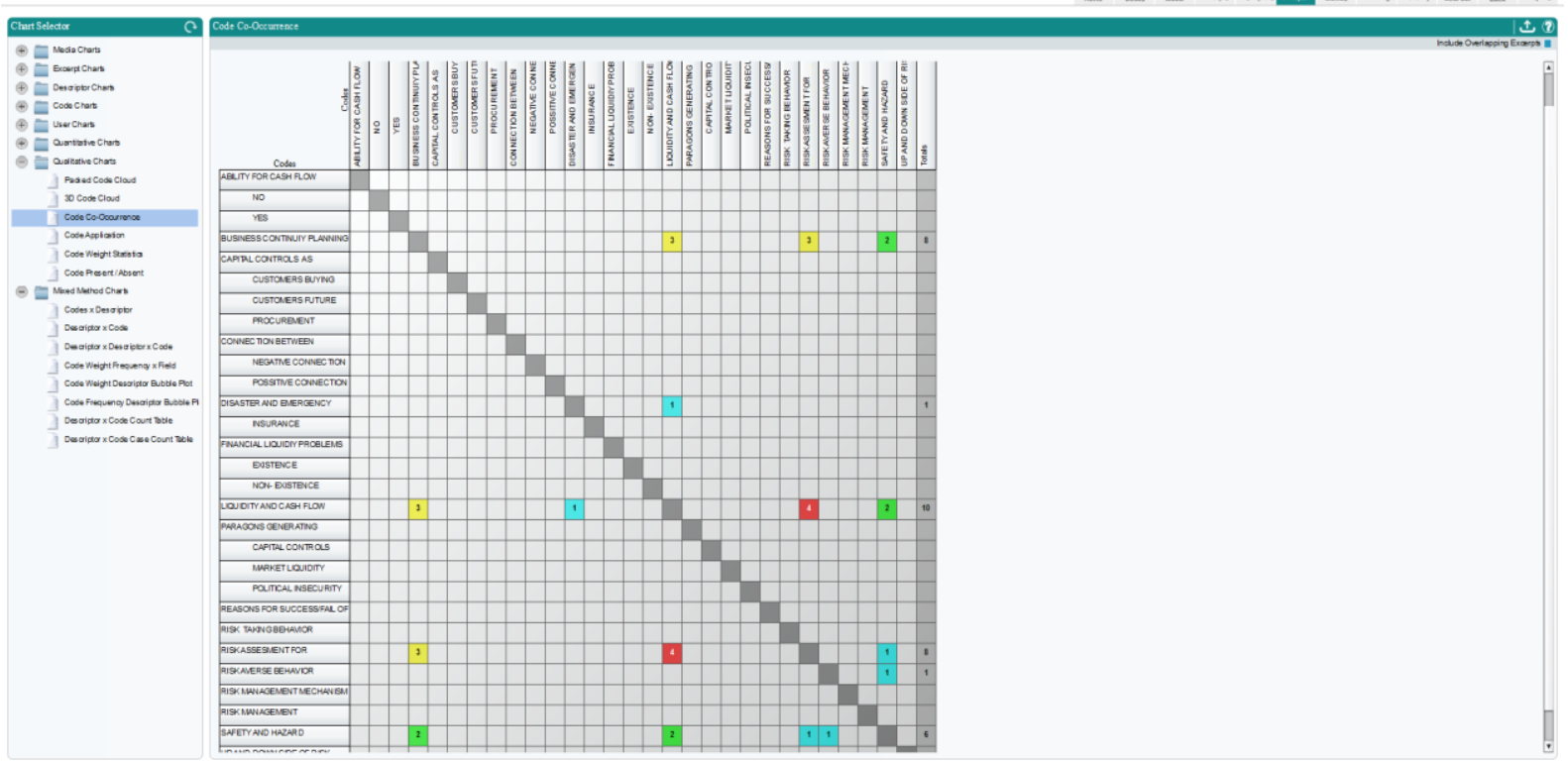

(9)

8: Codes' co- occurence

Another important finding was that when the risk management mechanisms succeeded, their success was only on the basis of business sustainement. They weren't used on the basis of development of any kind. For the SMEs that participated in the research, growth was out of the question. Such perception of things is very pathogenous.

Another important finding was that their customers loosing gradually their consumeristic power as they tend to consume less by the years something which is vividly depicted by the shrinking of the companies' turnover. Such consumeristic behavior in addition to the difficulties in bank financing and the overall climate, create important liquidity problems, as the respondents underlined.

Finally, it was obvious from the answers that the whole negative financial climate in the Greek market frustrates the SMEs' business owners who are able, for the time being, to achieve their preservance only because they have small business to run without the burden of any loans.

Such findings, as were described in the previous paragraphs, are indicative of a negative climate in the Greek economy in which SMEs in general and in our case, SMEs in the retail sector are struggling to survive. Their risk management mechanisms, when they exist are not sophisticated, mainly informal, and they find many financial impediments in their way which prevent them from operating in the right direction. In such climate and under the certain circumstances, which also bring liquidity problems, growth is out of the question, while sustainability is very difficult to be achieved and is not quite clear if it will be the case in the near future. Under such circumstances was not strange that all respondents declared that they are risk avesre when they were asked.

\section{Answer to the research question}

As we discussed in the main findings part, the financial impediments which interfere negatively with the Greek SMEs' risk management mechanisms while they are trying to overcome their financial risks, are the general unstable financial climate, the political unstable climate, the capital controls and the lack of bank financing. Such impediments prevent the companies' risk management mechanisms to operate and create a safe path for the companies in order to overcome their financial risks.

\section{Connection between main findings and previous research on the topic}

As Vlaar et al. (2006, cited in Giannacourou et al., 2014) indicated, uncertainty seems to be a decisive factor for SMEs, something which was obvious from the respondents' answers who stated that the financial and political uncertainty were two major paragons in shaping their business.

Zairis (2015) and Malkoutzis (2016), indicated that the majority of SMEs facing difficulties in accessing banking finance, thus they face liquidity problems. That was found to be one of the main financial impediments that SMEs' risk management mechanisms are facing. "Such problem creates vast liquidity problems" as a respondent indicated.

According to previous studies (NBG, 2016) political uncertainty and capital controls made Greek SMEs to decline in 2015 for $15 \%$ while in micro enterprises, which were the key sample of this research, that percent was almost $23 \%$. This is in 

accordance with the findings of the study which indicated that political uncertainty and capital controls were two of the major financial impediments to their risk management mechanisms.

An important element of previous studies which the researcher waiting to find in his responses, was what Chrysopoulos (2016) underlined by stating that the heavy taxation of the last years is eventually going to lead SMEs to extinction. None of the respondents mentioned anything about the heavy taxation as an impediment or as a risk. There is one possibility that the general negative financial climate that the respondents underlined could have included the heavy taxation too, but this is something that need to be investigated in a deeper way as it wasn't obvious in any of the given answers.

From the three elements that Jindrichovska (2013) identified in financial management, (1) liquidity and cash flow management, (2) long- term asset acquisition, (3) funding, capital structure and cost funding, the respondents declared that they only use the first.

In terms of risk appetite, all of the respondents said that they are risk averse due to the general financial climate, something which is in accordance with what Borges et al. (2012) indicated when he stated that the economic behavior is usually influenced by the perception of the decision maker which accordingly is influenced by the social- economic characteristics of the market and the assets of their companies.

The majority of the respondents stated that their risk management mechanisms, due to the previously mentioned financial impediments, cannot predict the patterns in their customers' consumeristic behavior and cannot create any models at all due to the unstable environment. Such answers were in accordance with previous studies as Courtney et al. (1997, cited in Karaoulanis, 2015a) indicated when they stated that the interaction of multi- dimension uncertainties create a virtually impossible to predict future. This is a major finding because it clearly states why the general climate and the respective financial impediments can be fatal enemies of any risk management mechanism which has the objective to maximize the potential of success and accordingly to minimize the probability of potential future loss (Colier et al. (2007, cited in Cuzdriorean, 2014).

From the three types of risk that presented by the NSW Department of State and Development (2005), the big majority of the respondents said that they mainly use uncertainty- based risk and hazard- based risk management mechanisms, even in simple forms like an insurance policy contract or cash- flow management mechanisms. This is also in accordance with the finding that all the respondents were risk averse something which can easily explain why they didn't use any kind of opportunity- based risk management mechanism, which is the third type.

Finally, according to Hubbard (2009), the risk management success/ failure spectrum comprises of five levels: best, better, baseline, worse and worst. From the responses, we can classify the risk management mechanisms, the SMEs in question use, mainly in two categories, the "baseline" because we found that the managers use mainly their intuition as they don't trust formal or sophisticated risk management techniques and the "worst", because although the methods they use seem to be ineffective due to the whole financial climate and also due to their simplicity and informality, they tend to have great confidence in them as they are not willing, in their majority, to implement more sophisticated ones in the near future. They believe that they can continue handling the whole situation successfully on the short and long run.

From this classification is more than obvious that the risk management mechanisms are in embryonic state and they are ineffective. This is a vicious cycle situation. Risk management cannot operate effectively due to financial impediments, which create uncertainty and economic imbalance, which contributes to the whole market in a way that strengthens the financial impediments and create more burdens in the risk management mechanisms which are not able to work effectively. In such situation managers are risk averse which means that there is absolutely zero possibility to try to expand. This kind of introversion is possible to eliminate SMEs in the near future.

\section{Main findings' importance and implications}

The importance of the main findings is huge as they can have many implications in the real market and society as well. Greek SMEs are the back bone of the Greek society and as they are the vast majority of the Greek companies operating nowadays, anything that creates impediments in their sustainability and growth has implications to the whole Greek society.

The main findings indicated two major issues, that there are several financial impediments that prevent their risk management mechanisms to be effective enough and that Greek SMEs in the retail sector don't use any kind of sophisticated risk management mechanisms.

The societal implications of the findings are going to be huge on the basis that will help SMEs realizing some major problems they have in order to achieve their development. That will create more new job positions, thus a chain reaction which will fuel the development of all Greek market and relieve the whole Greek society which today suffocates under the financial crisis.

\section{Results' limitations}

The result limitations are mainly focused on the sample which was not representative enough. As the researcher chose companies easily reachable, that created a bigger bias than if the sample was i.e. systematic (Queensland Health, 2007). The researcher was not able to capture the whole picture as he wasn't able to reach companies from different market segments, like services, technology etc. or companies from different locations in the country as the location of the market where the company operates can be a decisive element in its development or sustainability. 

Due to time and budget limitations, the research restrained in a specific area as it examined the responses of SMEs' executives in a specific location (Thessaloniki), which means that we had the bias of a non- national wide sample.

Alao, the research didn't take into account demographics like the educational level of the company owners, their age etc. Such parameters are important as they can determine how wide the managers' perspectives are about crucial issues such as market forecasting, investing, risk management implementation etc. It is obvious that such limitation affected the overall research results and especially their reproducibility.

The research was limited to micro SMEs which operating with less than 10 employees, something which made impossible to expand the results in a more holistic way regarding SMEs as a whole.

Finally, the sample included only 15 companies. Such number made the research doable, but created the bias of a nonbig sample, thus created reproducibility issues.

\section{Quality criteria of the research results}

Limitations like the specific sample, which was restrained to retail SMEs with under 10 employees which operate in the area of Thessaloniki, generated a lack of high degree of reproducibility.

Also, such limitations created problems in terms of transferability, as it is questionable how much such cases are representative as the small sample (15 companies) and the area restriction made such representation doubtful (Denscombe, 2010).

\section{Future research}

The SMEs issue is a very sensitive one and has bothered scientists for many years. One very interest future research topic can be why SMEs in Greece do not use formal or complex risk management mechanisms while operating in such unstable environment. Such research can be expanded in order to include a country wide sample of SMEs in order to give us a more spherical idea on the subject. This kind of research would be an extension of the current one as it will deal more effectively with the problem in hands and will shed some light on the reasons that prevent Greek SMEs from using such mechanisms

Another future research could be the connection of risk management and the educational level of the SMEs' owners, a parameter which seems to be quite important as i.e. the low educational level can explain why SMEs' managers are acting more on intuition and not on a more professional base. Also, a wider education can be a decisive paragon in widen the managers' perspectives thus the use of risk management mechanisms.

Another potential research topic could be the comparison between SMEs in Greece and the EU in order to underline the problems Greek SMEs are facing and to suggest risk management mechanisms that they could use in order to solve them. That can identify potential similarities between Greek SMEs and the ones from the South European countries.

Another suggestion could be to investigate how risk management mechanisms can be improved in order to provide solutions even in turbulent and unstable financial environments such as the Greek one. Under that prism can be investigated how risk management mechanisms can take into account asymmetric information in order to create i.e. forecasting models where no one seem that can.

\section{Conclusions}

This research was focused in Greek SMEs which operate in the retail sector, are family owned and have less than 10 employees. The companies that were examined via the questionnaires were operating in the clothes, furniture, food and beverage, drugs industries. The findings of the research proved two main points. Firstly, that such SMEs use only informal risk management mechanisms and they don't have separate risk management departments or sophisticated risk management mechanisms. Secondly, that there are several financial impediments which prevent event such informal mechanisms to operate effectively. Such impediments are the general unstable financial and political climate, the capital controls and the general liquidity problems which also are associated with the limited access to bank financing. Even when the companies feel that they can handle their financial problems, in fact they are doing that more on an intuition and experience base, something which can easily be proved disastrous in the long run.

\section{REFERENCES}

Aven T., 2012. "The risk concept- historical and recent development trends". Reliability Engineering and System Safety Journal. Elsevier. Vol.99, pp. 33-44.

2 Borges J.; Machado J., 2012. "Risks and Risk Management Mechanisms: An Analysis of the Perceptions of Producers of Agricultural Commodities" Interdisciplinary Journal of Research in Business. Vol. 2(5), pp.27- 39).

3 Bowen, G.A. 2008, "Naturalistic inquiry and the saturation concept: a research note", Qualitative Research, vol. 8, no. 1, pp. 137-152.

4 Brustbauer, J. 2016, "Enterprise risk management in SMEs: Towards a structural model", International Small Business Journal, vol. 34, no. 1, pp. 70-85. 
International Journal of Management and Information Technology

5 Carbó-Valverde, s. Rodríguez-Fernández, F. \& Udell, G.F. 2016, "Trade Credit, the Financial Crisis, and SME Access to Finance", Journal of Money, Credit and Banking, vol. 48 (1), pp. 113-143.

6 Chrysopoulos, 2016. "Greece at Top of Small-Medium Business Taxation" Greekreporter.com [online]. Available at:< http://greece.greekreporter.com/2016/05/16/greece-at-top-of-small-medium-business-taxation/> [Accessed 29 January 2017].

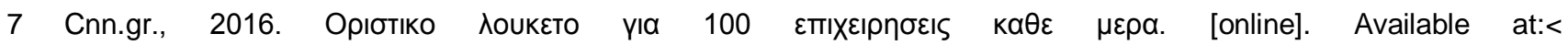
http://www.cnn.gr/money/epixeiriseis/story/39726/oristiko-loyketo-gia-100-epixeiriseis-kathe-imera> [Accessed 3 February 2017].

8 Codex.vr.se., n.d. Professional ethics. [online]. Available at:< http://www.codex.vr.se/en/forskarensetik.shtml $>$ [Accessed 4 February 2017].

9 Cuzdriorean, D.D. 2014, "SMEs financial risk management assessment in an emerging country: a sad reality of if and cons", African J. of Accounting, Auditing and Finance, vol. 3, no. 3, pp. 224.

10 Denscombe, M. 2010, The good research guide: for small-scale social research projects, 4th edn, Open University Press, Maidenhead.

11 Ec.europa.eu., n.d., What is a SME? [online]. Available at:< http://ec.europa.eu/growth/smes/business-friendlyenvironment/sme-definition_el> [Accessed 2 February 2017].

12 European Foundation for the Improvement of Living and Working Conditions, EF/12/47/EN 5 of 2013 on the Restructuring in SMEs: Greece.

13 Farid J.A., 2014. What is Risk: A Practitioner's Guide to Risk Management. UK: Palgrave Macmillan.

14 Falkner Eva Maria, Martin R.W. Hiebl, (2015)," Risk management in SMEs: a systematic review of available evidence ", The Journal of Risk Finance, Vol. 16 Iss 2 pp. 122 - 144.

14.1Financial Times Lexicon., n.d. "Definition of gross value added GVA" [online] Available at:< http://lexicon.ft.com/Term?term=gross\%20value\%20added\%20GVA> [Accessed 28 January 2017].

15 Georgousopoulou, M., Chipulu, M., Ojiako, U. \& Johnson, J. 2014, "Investment risk preference among Greek SME proprietors: a pilot study", Journal of Small Business and Enterprise Development, vol. 21, no. 1, pp. 177-193.

16 Giannacourou M., Kantaraki M., Christopoulou V., 2014. "The perception of crisis by Greek SMEs and its impact on managerial practices" Procedia- Social and Behavioural Sciences. Vol.175, pp.546-551.

17 GSEVEE; ESEE; KEEE; TEGR; SETE, 2014. The development of SMEs in Greece. Policy document. Athens: GSEVEE; ESEE; KEEE; TEGR; SETE

18 HBA, 2013. Access to Finance for SMEs in Greece: Report of High Level Meeting of Representatives [pdf]. HBA. Available at:< http://www.hba.gr/6Mme/UplFiles/deltia_typou/Report_Access_to_Finance_for_SMEs_in_Greece.pdf > [Accessed 3 February 2017].

19 Hubbard D., 2009. "The failure of Risk management: Why it's broken and How to fix it".New Jersey: Willey J. \& Sons, Inc.

20 Hyz A., 2011 "Small and Medium Enterprises (SMEs) in Greece - Barriers in Access to Banking Services. An Empirical Investigation". International Journal of Business and Social Science. Vol 2(2), pp. 161-165.

21 Jundrichovska I., 2013. "Financial management in SMEs" European Research Studies Journal. Vol. 16(4), pp.80-96.

22 Kaplanoglou, G., Rapanos, V.T. \& Daskalakis, N. 2016, "Tax compliance behaviour during the crisis: the case of Greek SMEs", European Journal of Law and Economics, vol. 42, no. 3, pp. 405-444.

23 Karaoulanis A., 2015a. "Strategy Formulation for SMEs in Greece's Uncertain Environment". Journal of Social Sciences Research, Vol 9(2), pp.1800-1803.

24 Karaoulanis A., 2015b. "Combination of different perspectives in strategy formulation". Journal of Social Sciences Research, Vol 9(2), pp. 1854-1857.

25 Karaoulanis A., 2017. "Social Dimensions of Distance Post- Graduate Education in Greece". International Journal of Computers and Technology. Vol 15(14), pp. 7472- 7485.

26 Lacina L.;Vavrina J., 2013. "The impact of financial and economic crisis on SME's in Greece and Ireland". Acta Universitatis Agriculture et Silviculturae Mendelianae Brunensis. Vol 111(4), pp.1005-1016.

27 Malkoutzis N., 2016 "Greek paradoxes hold back business". E-kathimerini.com [online]. Available at:< http://www.ekathimerini.com/209339/article/ekathimerini/business/greek-paradoxes-hold-back-business> [Accessed 29 January 2017]. 
International Journal of Management and Information Technology

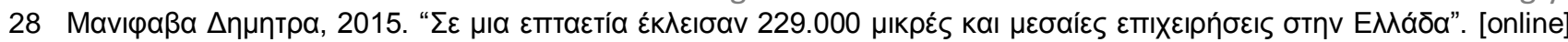
Kathimerini.gr. Available at:< http://www.kathimerini.gr/824685/article/oikonomia/epixeirhseis/se-mia-eptaetiaekleisan-229000-mikres-kai-mesaies-epixeirhseis-sthn-ellada> [Accessed 26 January 2017].

29 NBG, 2016. "Survey of Greek SMEs.January 2016" [online]. National Bank of Greece. Available at:< https://www.nbg.gr/en/the-group/press-office/e-spot/reports/smes-2015-h2-en> [Accessed 29 January 2017].

30 NSW Department of State and Regional Development. 2005. Risk management guide for small business. [pdf]. Small Business Development Division. Available at:< http://www.significanceinternational.com/Portals/0/Documents/2005sme-risk-management-guide-global-risk-alliance-nsw-dsrd.pdf> [Accessed 4 February 2017].

31 O'Reilly, M. \& Parker, N. 2013; 2012;, "'Unsatisfactory Saturation': a critical exploration of the notion of saturated sample sizes in qualitative research", Qualitative Research, vol. 13, no. 2, pp. 190-197.

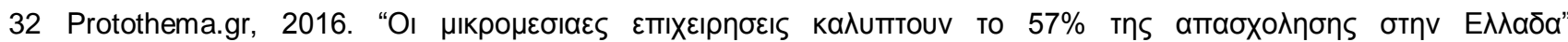
Protothema.gr [online]. Available at: < http://www.protothema.gr/economy/article/599599/oi-mikromesaiesepiheiriseis-kaluptoun-to-57-tis-apasholisis-stin-ellada/> [Accessed 26 January 2017].

33 Queensland Health, 2007. "Queensland 'Stay On Your Feet" Community Good Practice Toolkit- Phase 1 materials: Surveys/questionnaires". [pdf]. Queensland Health. Available at: http://www.health.qld.gov.au/stayonyourfeet/documents/33345.pdf> [Accessed 20 November 2016].

34 Wymenga P., Dr. Spanikova, Dr. Derbyshire J., Barker A., 2011. "Are EU SMEs recovering from the crisis?" [pdf] Rotterdam: Annual Report on EU Small and Medium sized Enterprises 2010/2011. Available at:< http://ec.europa.eu/DocsRoom/documents/15770/attachments/1/translations/en/renditions/native> [Accessed 28 January 2017].

35 Yin, R.K. 2014. Case Study Research: Design and Methods. 5th Ed. Los Angeles: Sage Publication.

36 Zairis A., 2015. "The Effects of the Financial Crisis on the Performance of Greek SME's". International Journal of Business, Humanities and Technology. Vol 5(6), pp. 29-37.

\section{APPENDIX A: INFORMED CONSENT FORM}

\section{Researcher:}

Karaoulanis Andreas

Tel: 0030123456789

E mail: researcher@gmail.com

Affiliation: Stockholm University/ DSV department

\section{Information about the research:}

Aims: The aim of this research is to identify the financial impediments that have negative impact to the risk management mechanisms in Greek SMEs in contemporary Greece.

Methods: The strategy that was chosen is the survey one. In terms of data gathering, the research uses e- mail questionnaires or handed in face-to-face ones. Finally the analytic method that will be followed is the qualitative one.

Anticipated outcomes: The researcher strives to find out what are the financial impediments that have negative impact to the Greek SMEs' risk management mechanisms while trying to overcome their identified financial risks.

\section{Expectations about the participants' contribution:}

- The participants are expected to answer some open ended questions.

- The estimated time for answering them is no more than 10 minutes in total. No expenses needed.

- The participants will be given a free copy of the final report outcome.

\section{The right to withdraw consent:}

Participants are not obliged to continue in their role during this research if, at some subsequent stage, they no longer wish to. The consent form is not a contract that binds a person to the task of helping with the research. It is therefore very clear that participants have the right to withdraw their consent at any time.

\section{Confidentiality and security of data:}

- The researcher will treat the data provided by the participants under strict confidentiality and according to the Educational Researcher, Code of Ethics of the American Educational Research Association Approved by the AERA Council.

- The researcher will not mention any names in his research and all data acquired will be treated under strict anonymity. 
nternational Journal of Management and Information Technology

- $\quad$ All email responses will be treated under strict confidentiality and it is the researcher's obligation to permanently delete them after the end of the research.

Signature of the participant and date:

I have read and understood the written details provided for me about the research and agree to participate in the project.

SIGNATURE

Signature of the researcher and date:

SIGNATURE

\section{APPENDIX B: DATA COLLECTION PROTOCOL QUESTIONNAIRE}

\section{No 1}

Researcher's details:

Name: Karaoulanis Andreas

E- mail: karaoulandre@gmail.com

Tel. number: 0030-6956206876

Affiliation: Stockholm University Sweden

The purpose of this questionnaire is to investigate the financial factors that have negative influence to the risk management mechanisms that Greek SMEs using in order to face successfully their financial risks.

Please make sure if possible that you will return your answer as soon as possible in order to help the research progress.

Please return the questionnaire as soon as you will answer the questions provided in the following e- mail: karaoulandre@gmail.com. If you don't have access to an email, please contact the researcher in the 0030-6956206876 in order to let him pick the questionnaire from your premises.

Please answer to the following questions by using the space provided in a concise and clear way.

1. Can you please describe the risk management process, if any, in your company?

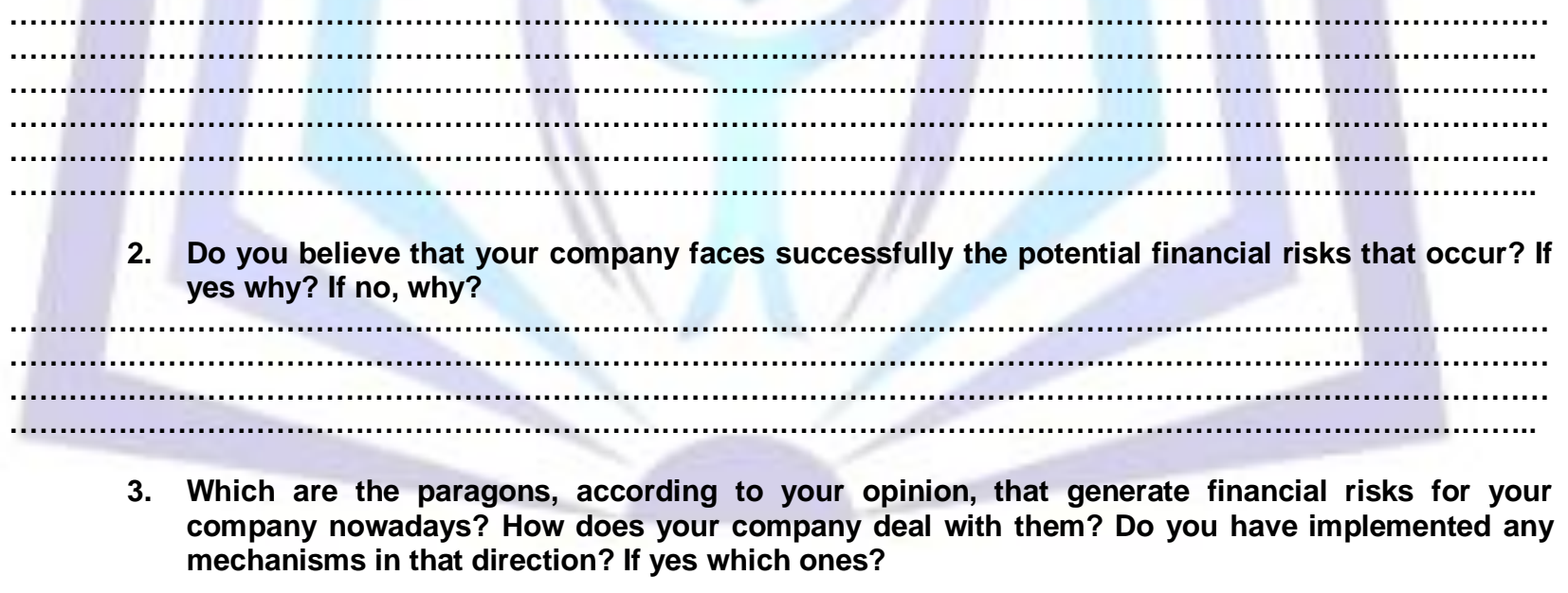

Which are the paragons, according to your opinion, that generate financial risks for your mechanisms in that direction? If yes which ones?

4. Does your company face any financial problems? If yes, is there any connection between them and the current general financial climate in Greece? If there is, please describe it.

5. According to your opinion, what are the reasons that the risk management mechanisms of your company fail/ succeed in dealing with your company's financial risks nowadays? 
5a. Do you use any of the following risk management mechanisms: Disaster and emergency planning, business continuity planning, safety and hazard management tools and techniques, up and down side of risk assessment in terms of pursuing an opportunity, liquidity and cash flow management? If yes, please tell in what ways and how effective they are.

5b. What amount of financial risk are you willing to satisfy for your company? Do you believe that this amount is correlated in any way with the financial situation in the Greek market?

5c. Do you believe that you are able to implement the appropriate liquidity and cash flow management for your company? If not, which financial factors are creating impediments to such process?

5d. Do you believe that your company's liquidity management is affected in any way by the capital controls? Do you believe that capital controls are a financial risk which creates problems in your company's risk assessment? If yes in which ways? Please clarify.

Thank you very much for your participation. 
International Journal of Management and Information Technology APPENDIX C: DEDOOSE SCREENSHOTS

\section{The project's home page}

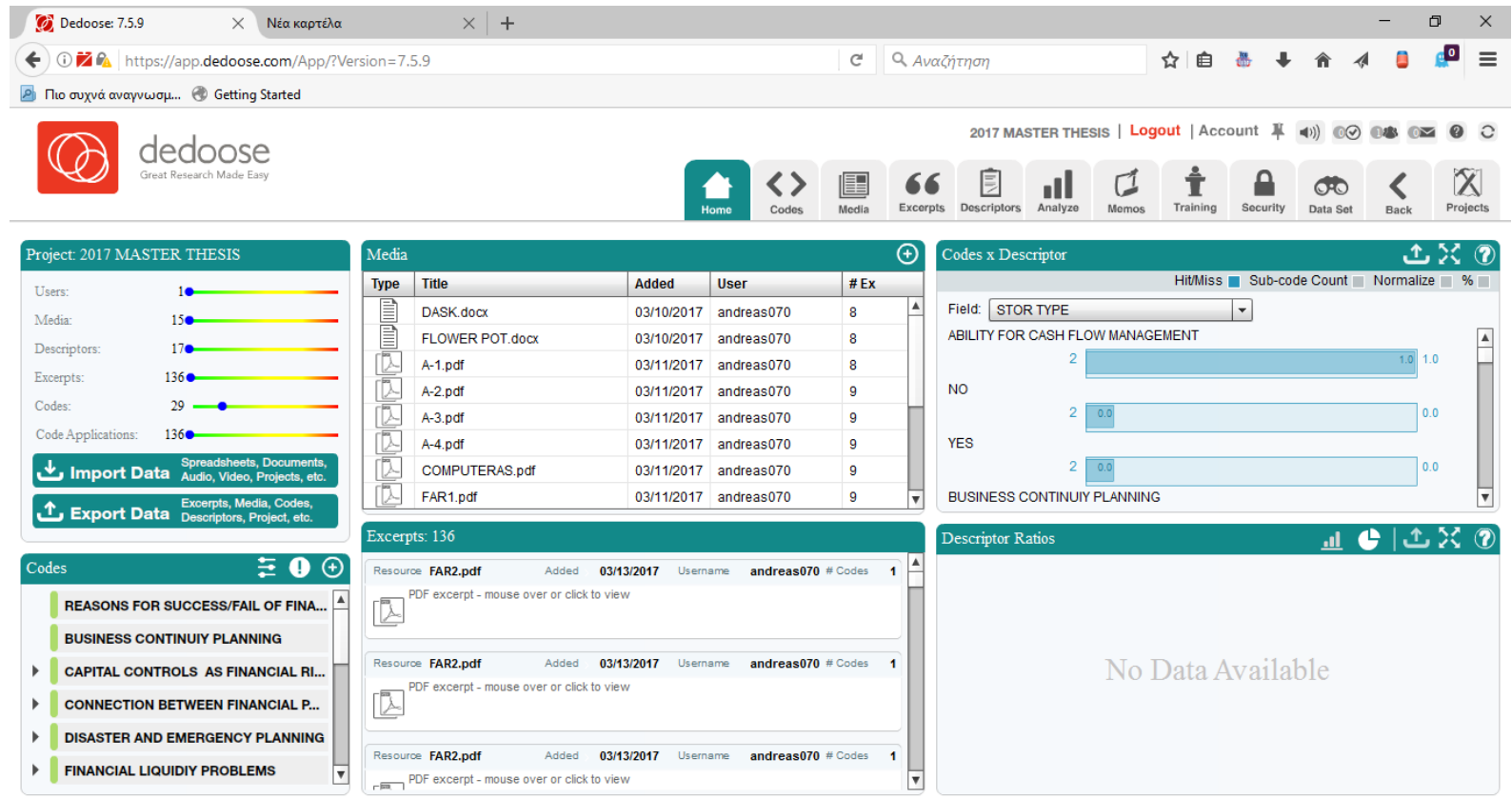

\#

2. The codes

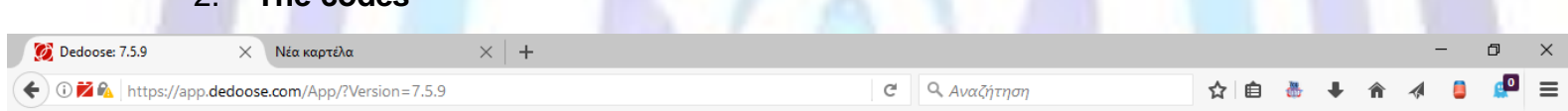

[8] חio ouxứa avaquwou... Getting Started

(2) dedoose

2017 MASTER THESIS | Logout | Account $¥$ 41) 00

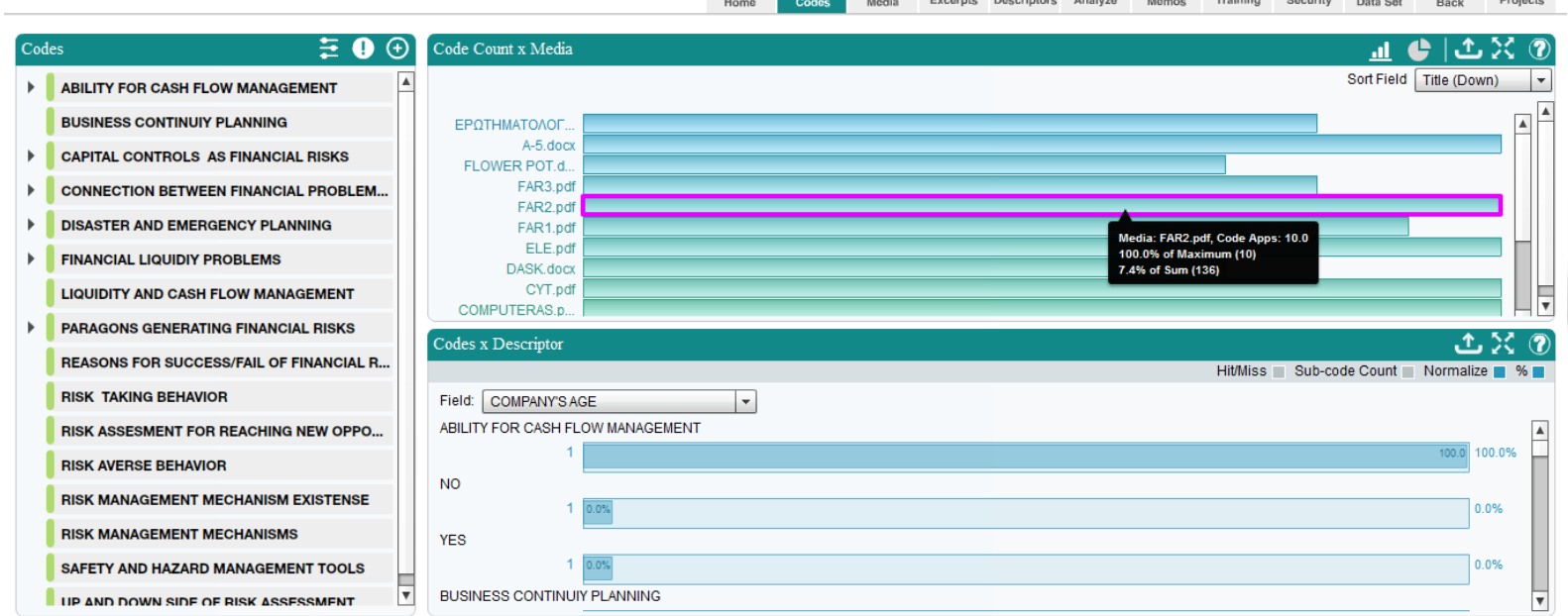

月 
ISSN $2278-5612$

Volume $12 \mathrm{Number} 1$

International Journal of Management and Information Technology 3. The excerpts

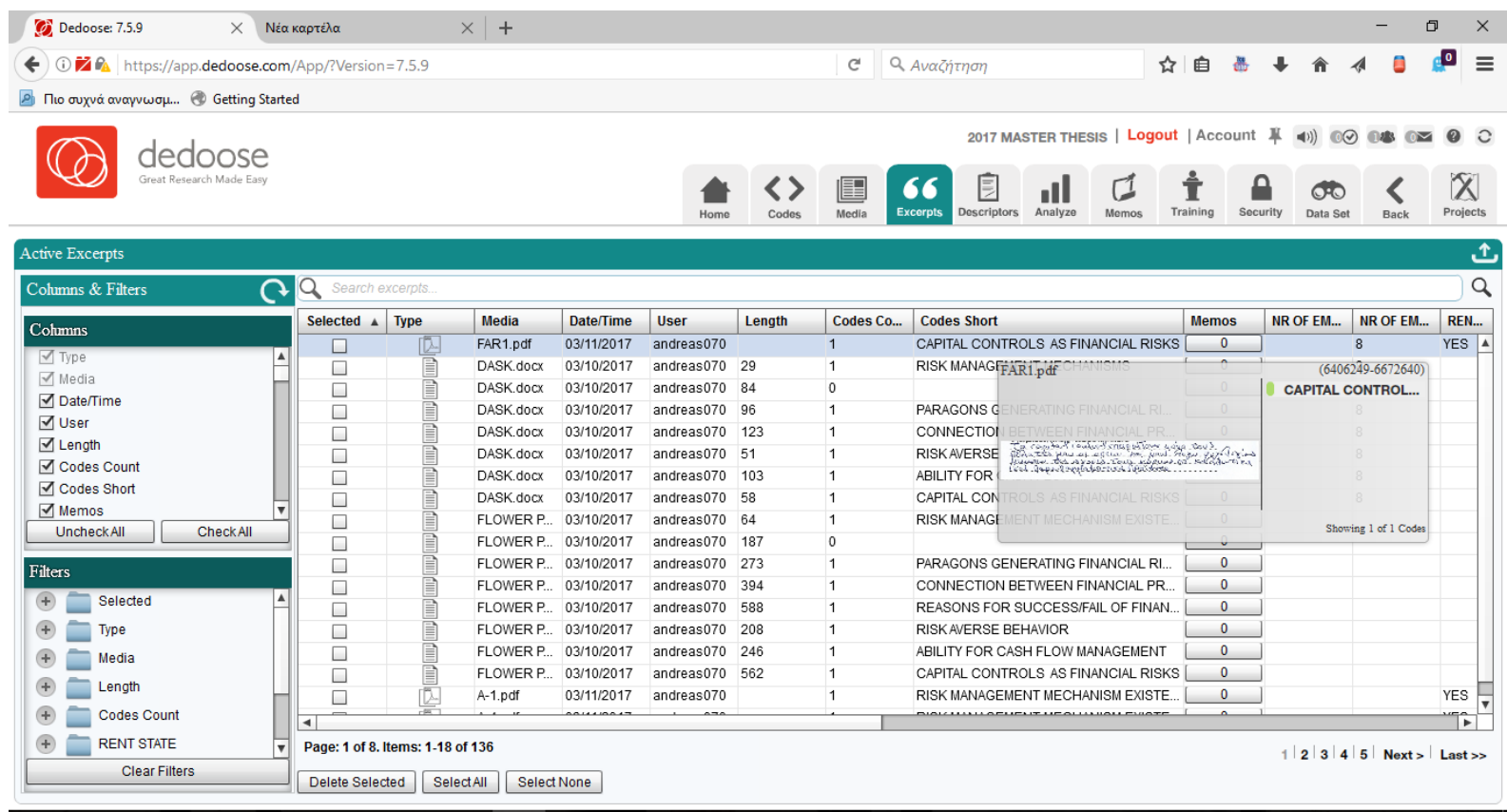

\#

\section{Code application}

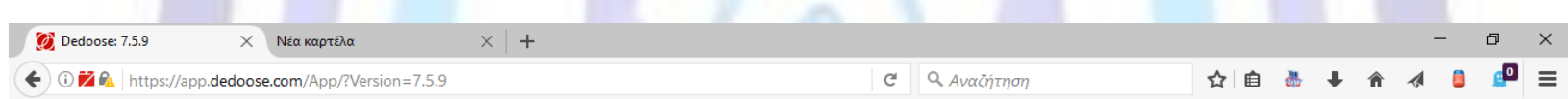

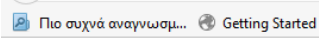

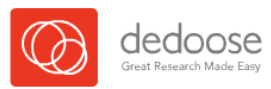

2017 MASTER THESIS | Logout | Account $\Psi$ 4) ) $\odot$ ()

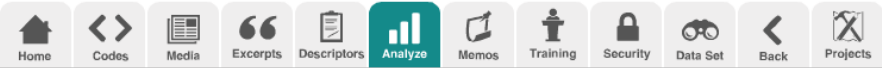

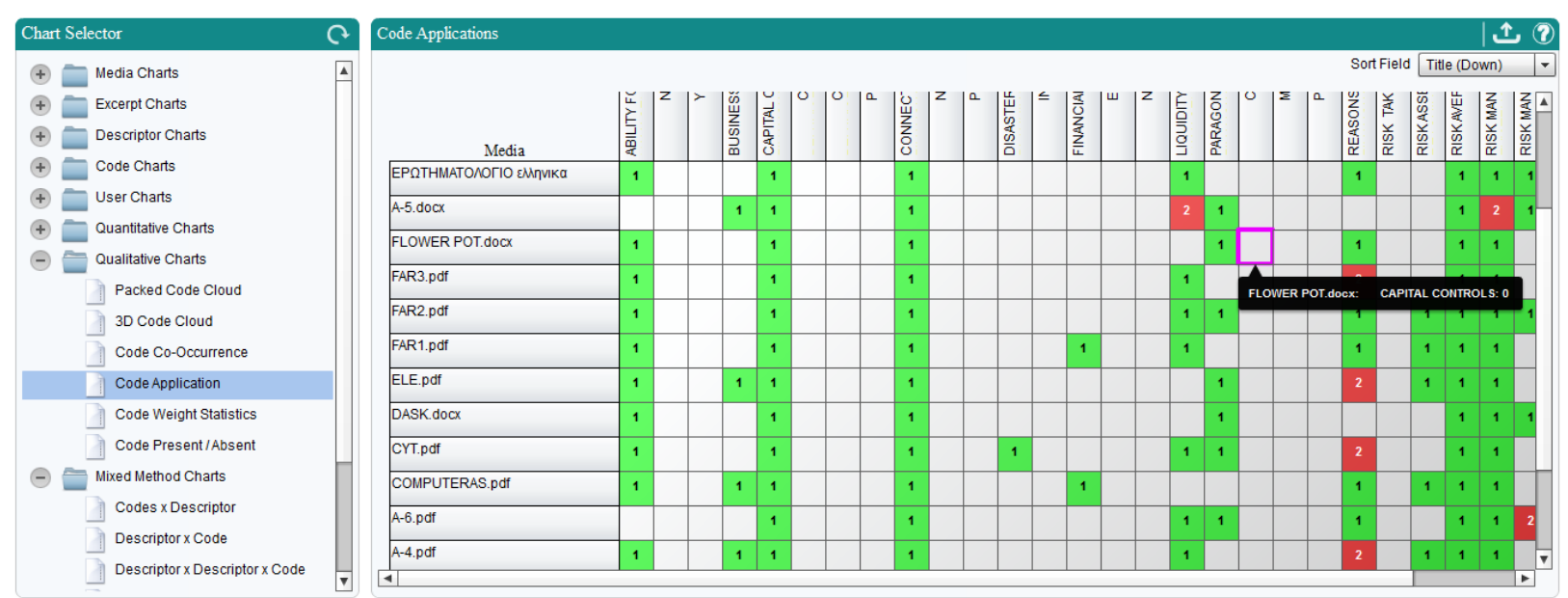

\# 
nternational Journal of Management and Information Technology 5. The uploaded data (questionnaires) and how they are connected to the codes

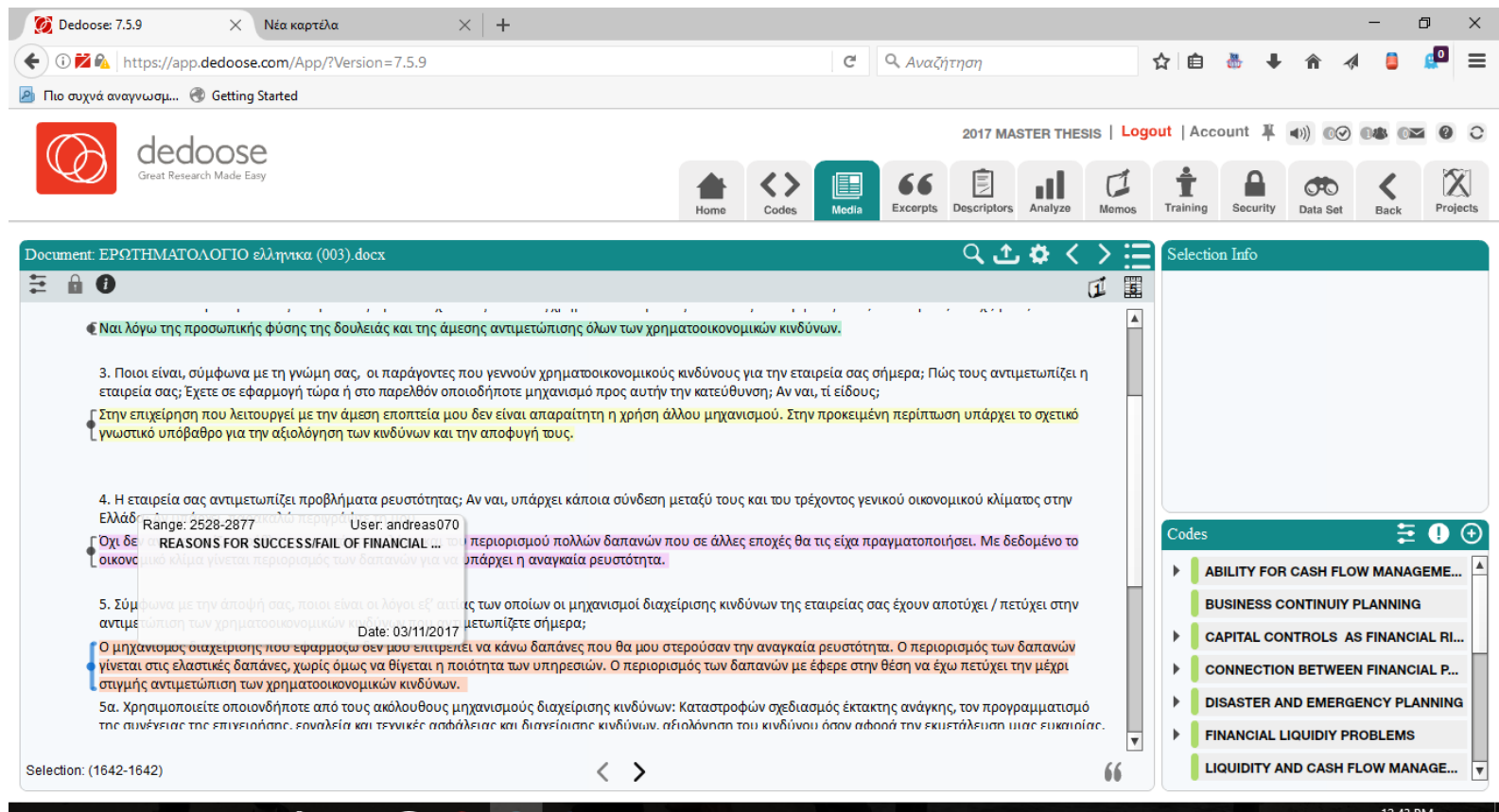

\# 0 四

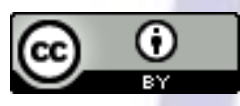

This work is licensed under a Creative Commons Attribution 4.0 International License. 